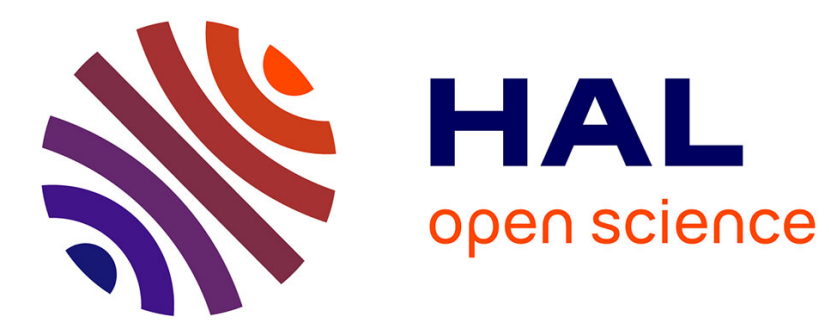

\title{
Polypropylene foam behaviour under dynamic loadings: Strain rate, density and microstructure effects
}

\author{
Rémy Bouix, Philippe Viot, Jean-Luc Lataillade
}

\section{To cite this version:}

Rémy Bouix, Philippe Viot, Jean-Luc Lataillade. Polypropylene foam behaviour under dynamic loadings: Strain rate, density and microstructure effects. International Journal of Impact Engineering, 2009, 36, pp.329-342. 10.1016/j.ijimpeng.2007.11.007 . hal-00871572

\section{HAL Id: hal-00871572 \\ https://hal.science/hal-00871572}

Submitted on 9 Oct 2013

HAL is a multi-disciplinary open access archive for the deposit and dissemination of scientific research documents, whether they are published or not. The documents may come from teaching and research institutions in France or abroad, or from public or private research centers.
L'archive ouverte pluridisciplinaire $\mathbf{H A L}$, est destinée au dépôt et à la diffusion de documents scientifiques de niveau recherche, publiés ou non, émanant des établissements d'enseignement et de recherche français ou étrangers, des laboratoires publics ou privés. 


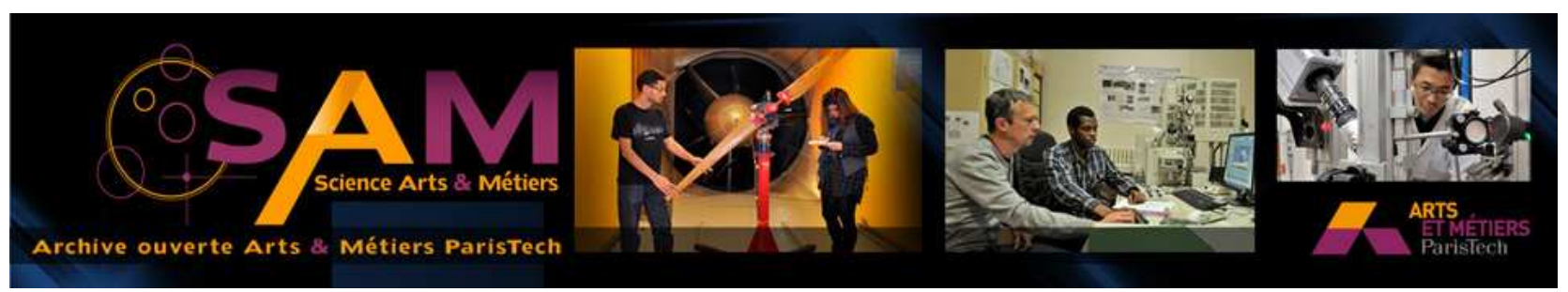

Science Arts \& Métiers (SAM)

is an open access repository that collects the work of Arts et Métiers ParisTech researchers and makes it freely available over the web where possible.

This is an author-deposited version published in: http://sam.ensam.eu

Handle ID: .http://hdl.handle.net/10985/7384

\section{To cite this version :}

Rémy BOUIX, Philippe VIOT, Jean-Luc LATAILLADE - Polypropylene foam behaviour under dynamic loadings: Strain rate, density and microstructure effects - International Journal of Impact Engineering - Vol. 36, p.329-342 - 2009 


\title{
Polypropylene foam behaviour under dynamic loadings: Strain rate, density and microstructure effects
}

\author{
Rémy Bouix, Philippe Viot*, Jean-Luc Lataillade \\ Arts et Métiers - ParisTech - Laboratory for Damaging and Reliability of Materials and Processes Engineering, Esplanade des Arts et Métiers 33405 Talence, Cedex, France
}

Keywords:

Polypropylene foam

Closed cells

High strain rate compression

Split Hopkinson Pressure Bar

\begin{abstract}
A B S T R A C T
Expanded polypropylene foams (EPP) can be used to absorb shock energy. The performance of these foams has to be studied as a function of several parameters such as density, microstructure and also the strain rate imposed during dynamic loading. The compressive stress-strain behaviour of these foams has been investigated over a wide range of engineering strain rates from 0.01 to $1500 \mathrm{~s}^{-1}$ in order to demonstrate the effects of foam density and strain rate on the initial collapse stress and the hardening modulus in the post-yield plateau region. A flywheel apparatus has been used for intermediate strain rates of about $200 \mathrm{~s}^{-1}$ and higher strain rate compression tests were performed using a viscoelastic Split Hopkinson Pressure Bar apparatus (SHPB), with nylon bars, at strain rates around $1500 \mathrm{~s}^{-1}$ EPP foams of various densities from 34 to $150 \mathrm{~kg} \mathrm{~m}^{-3}$ were considered and microstructural aspects were examined using two particular foams. Finally, in order to assess the contribution of the gas trapped in the closed cells of the foams, compression tests in a fluid chamber at quasi-static and dynamic loading velocities were performed.
\end{abstract}

\section{Introduction}

Cellular materials such as expanded polypropylene foams (EPP) are often used in large protective applications and passive safety for packaging (electronic components, aeronautical structures, food, etc.) or personal safety (helmets, knee-pads, etc.). They are also often used as core material for sandwich composite structures used in aircraft, naval, or automotive industries due to their lightness and their great capacity to absorb energy. For instance, the automotive industry uses these materials more and more as new technological solutions as structures or components for crash-box system energy absorbers, side door panel impact protections or seating systems to prevent submarining. In such applications the foams which are used are often designed to absorb the maximum energy and are generally subjected to severe loadings involving strain rates. For instance for the everyday use of an automotive crash-box, the foam used in this structure is stressed under quasi-static loadings but in case of pedestrian shocks or impacts the foam is subjected to dynamic compression and has to absorb the maximum energy to satisfy automotive regulations. Considering a foam crash-box with a thickness of $60 \mathrm{~mm}$ and an impact velocity of $40 \mathrm{~km} \mathrm{~h}^{-1}$ the strain rate imposed on the foam rapidly reaches $200 \mathrm{~s}^{-1}$. In case of

\footnotetext{
* Corresponding author. Tel.: +335568453 62; fax: +33556845366. E-mail address: philippe.viot@lamef.bordeaux.ensam.fr (P. Viot).
}

passenger safety, the foams used in side door panel impact protections could undergo high strain rates up to $1500 \mathrm{~s}^{-1}$ during lateral collisions at only $90 \mathrm{~km} \mathrm{~h}^{-1}$. Such strain rates are not maintained during the crash. From the engineering point of view the velocity of the deformation must be taken into consideration.

Therefore in order to optimize the design of these structures, the behaviour of which strongly depends on the foam being used, it is necessary to observe and understand the response of these materials under actual conditions of use. Then dynamic characterisations at high and medium strain rates [1] have to be investigated in experiments to provide reliable and realistic behaviour laws for FEM codes.

Quasi-static to dynamic loadings are then worked out to study the strain rate effect on the foam response using a conventional testing machine for quasi-static tests at the strain rate of 0.01 and $1 \mathrm{~s}^{-1}$, an original compression device based on a rotating flywheel [2] for tests at intermediate strain rates $\left(\sim 200 \mathrm{~s}^{-1}\right)$ and a Split Hopkinson Pressure Bar (SHPB) for dynamic tests $\left(\sim 1500 \mathrm{~s}^{-1}\right)$. Initially developed by Kolsky [3] to characterise metallic materials [4-6], this device also makes it possible to characterise other materials such as ceramics [7], concrete [8], rocks [9], composites [10] and more recently metallic cellular materials such as honeycomb or aluminium foam $[11,12]$. Nevertheless to characterise more compliant materials such as polymeric foams [13-15] or polymers [16] this apparatus has to be adapted because the impedance mismatch between polymeric cellular materials and ordinary metallic bars is 


\begin{tabular}{|c|c|c|c|}
\hline \multicolumn{2}{|c|}{ Nomenclature } & \multirow{2}{*}{$\begin{array}{l}\tilde{P}(\omega) \\
S\end{array}$} & \multirow{2}{*}{$\begin{array}{l}\text { Fourier transform of the strain at } x=0 \text { due to the } \\
\text { reflected wave } \\
\text { cross-sectional area of the specimen }\end{array}$} \\
\hline$A$ & cross-sectional area of the bar & & \\
\hline$c(\omega)$ & phase velocity & $S_{0}$ & initial cross-sectional area of the specimen \\
\hline$D$ & bar diameter & $u$ & axial displacement \\
\hline$d$ & $\begin{array}{l}\text { distance between the strain gage location and the non- } \\
\text { impacted end }\end{array}$ & $\begin{array}{l}v \\
Z\end{array}$ & $\begin{array}{l}\text { axial particle velocity } \\
\text { mechanical impedance }\end{array}$ \\
\hline$E$ & Young's modulus & & \\
\hline$E^{*}$ & complex Young's modulus & \multicolumn{2}{|c|}{ Greek letters } \\
\hline$E_{\mathrm{pl}}$ & plateau stress modulus & $\alpha(\omega)$ & attenuation coefficient \\
\hline$e^{p}$ & true strain & $\gamma(\omega)$ & propagation coefficient \\
\hline$F$ & normal force & $\varepsilon$ & conventional strain \\
\hline$\tilde{f}(x, \omega)$ & Fourier transform of function $f(x, t)$ at cross-section $x$ & $\dot{\varepsilon}$ & engineering stain rate in the specimen \\
\hline$f$ & frequency & $\lambda$ & wavelength \\
\hline$k$ & wave number & $\rho$ & specimen mass density \\
\hline$l_{0}$ & initial specimen length & $\sigma$ & normal stress \\
\hline \multirow[t]{3}{*}{$\tilde{N}(\omega)$} & Fourier transform of the strain at $x=0$ due to the & $\sigma_{\mathrm{pl}}$ & collapse stress \\
\hline & incident wave & $\varphi$ & volume fraction of cell edges in a unit volume \\
\hline & & $\omega$ & angular frequency \\
\hline
\end{tabular}

too large. The latter have thus been replaced by viscoelastic bars (nylon bars) in order to optimize the matching between the specimen and the bars [17-19].

The foam density is also investigated over a large range of densities from 34 to $150 \mathrm{~kg} \mathrm{~m}^{-3}$ as well as the influence of the foam microstructure on its behaviour, by comparing the response of two foams of different microstructures. Further investigations are also carried out to highlight the effect of the entrapped gas in the closed cells during quasi-static and dynamic loadings using a fluid chamber.

\section{Experimental procedure}

\subsection{Material and specimens}

The mechanical properties of these types of industrial cellular materials are well known under quasi-static compression [20] and also under large strain [21]. The mechanical behaviour of these foams at quasi-static compression is characterised by three phases (Fig. 1): (i) a linear elastic behaviour, (ii) a plateau stress, and (iii) a final stage, which consists of foam densification.

This particular stress-strain response to large compression is mainly related to the foam microstructure (Fig. 2) which is an aggregate of micro-closed cells delimited by bead walls. During the stress plateau phase the foam can undergo large compressive strains and absorb a considerable amount of specific energy [22].

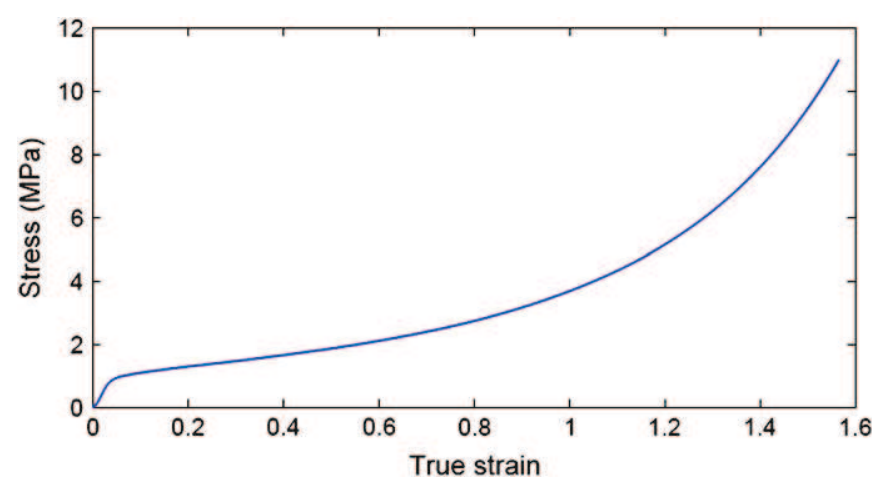

Fig. 1. Typical quasi-static stress-strain response of a foam.
The cell edges collapse by elastic or plastic buckling, while the faces of these closed cells bend and the bead walls mainly collapse by buckling. During dynamic compression tests, the degree of strength enhancement depends on the strain rate [14] but also on the complex microstructure of the foam and the entrapped gas in the closed cells $[23,24]$.

This particular microstructure of the expanded polypropylene foams is due to their manufacturing processes. The first step of this process consists in the pre-expansion of small polypropylene granulates into low density polypropylene beads of $30-50 \mathrm{~kg} \mathrm{~m}^{-3}$. These expanded plastic bead foams are injected into a custom designed steam chest mold, where individual beads are fused together under steam heat and pressure. The gas generates the expansion of these beads measuring only a few millimeters which agglomerate together to form the structure of the foam.

The microstructure of these foams varies considerably according to their density. An example of these different microstructures is easily observable in Fig. 3, which represents SEM observations of bead agglomerations and micro-closed cells for three different densities $\left(34,76\right.$ and $110 \mathrm{~kg} \mathrm{~m}^{-3}$ ). In order to quantify these foam microstructures, square samples of $8 \mathrm{~mm}$ to a side have been randomly picked up from the foam blocks (Fig. 5) in the three space directions and SEM analysis gave an estimation of mean cell dimensions.

The size of these beads and cells (apparent section size) varies according to the cross section but the high sampling evaluation on more than 400 measured cells for each density makes it possible to determine a mean cell dimension: Fig. 4 sums up these measurements.

Large differences are noticeable between the smallest density of $34 \mathrm{~kg} \mathrm{~m}^{-3}$ and the other foam densities (76 and $110 \mathrm{~kg} \mathrm{~m}^{-3}$ ). Indeed on the less dense foam, $65 \%$ of the cell surfaces measure less than $0.02 \mathrm{~mm}^{2}$ whereas for the other two densities nearly $45 \%$ of the cell surfaces measure less than $0.1 \mathrm{~mm}^{-2}$. The same conclusions can be made with regards to the mean edge lengths of the cells (Fig. 4d). It could also be noticed that the standard deviation of the cell edge length distribution is larger for foams of 76 and $110 \mathrm{~kg} \mathrm{~m}^{-3}$ than for the lowest one.

From these measurements a reasonable specimen volume of $23 \times 23 \times 23 \mathrm{~mm}$ has been chosen. Specimens are extracted from the middle of large EPP foam blocks of $750 \times 500 \times 200 \mathrm{~mm}$ which ensures the homogeneous density of the specimens by avoiding high density gradients near the outer surfaces of the foam blocks 


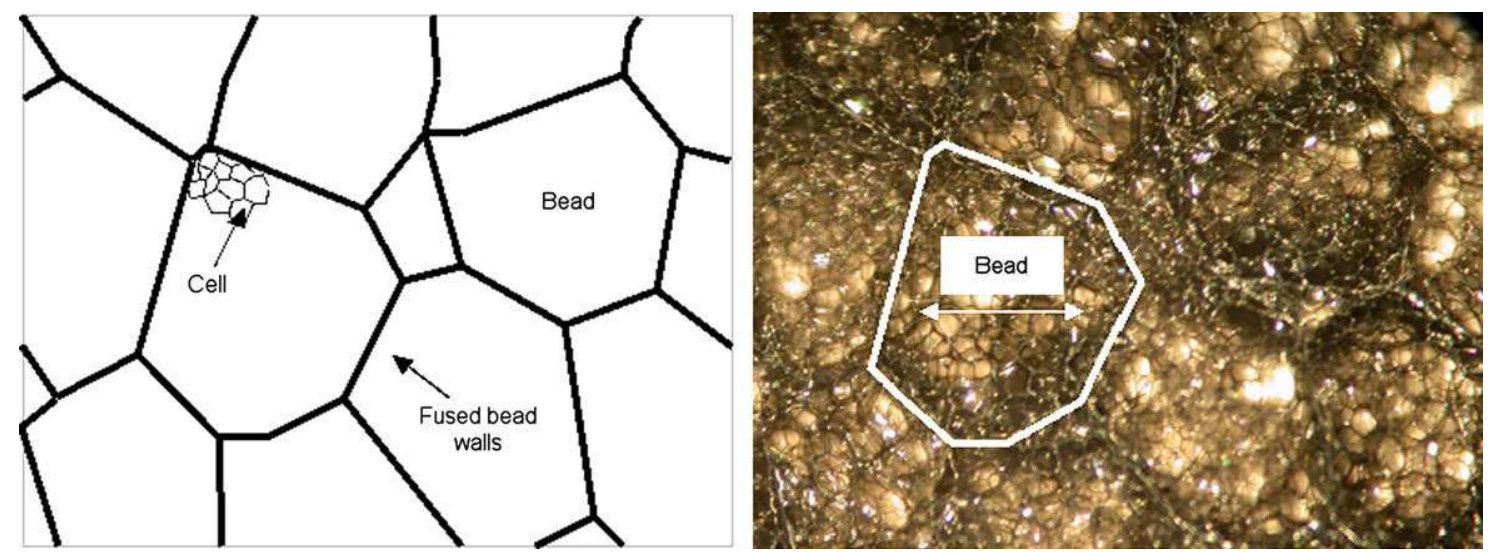

Fig. 2. Diagram and photograph of the EPP foam structure, beads and closed cells.

a

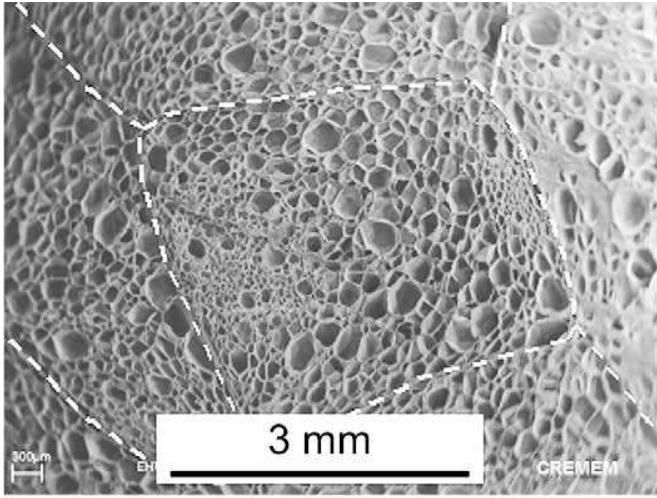

b

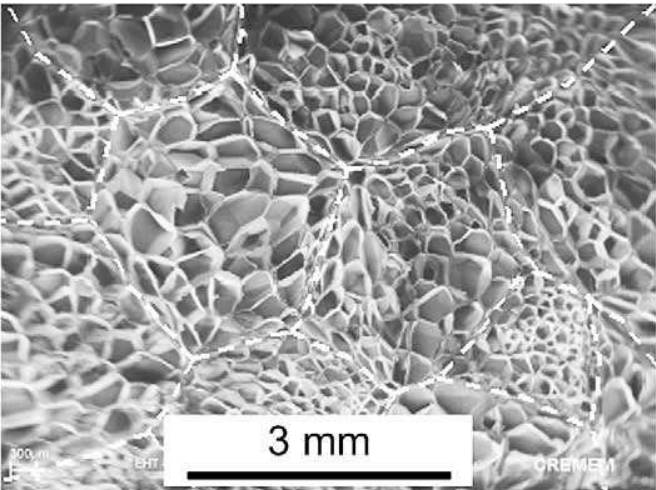

C

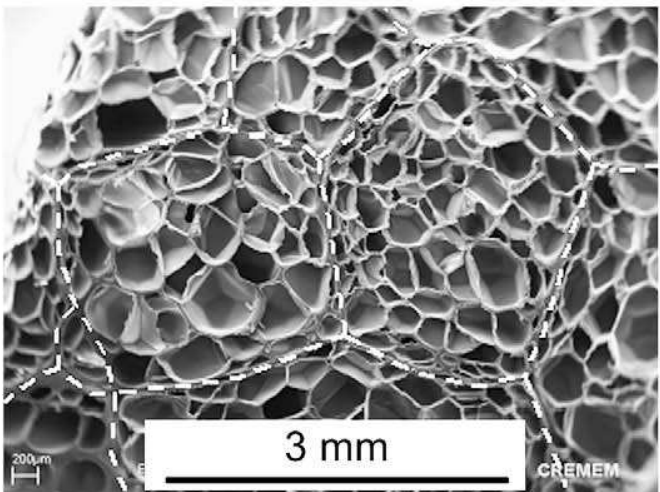

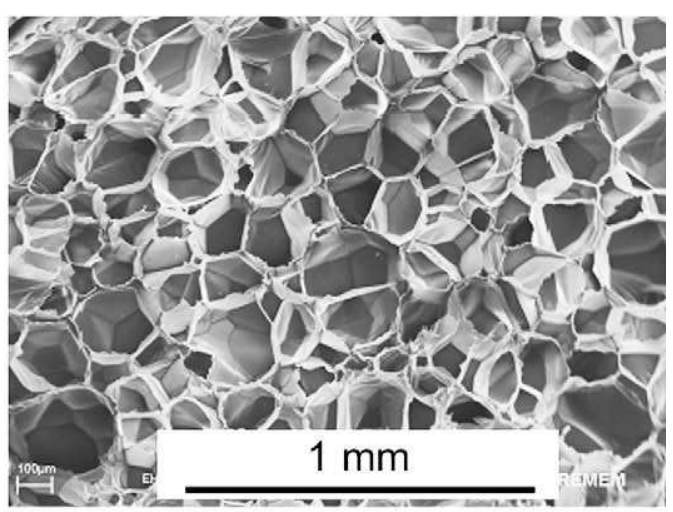
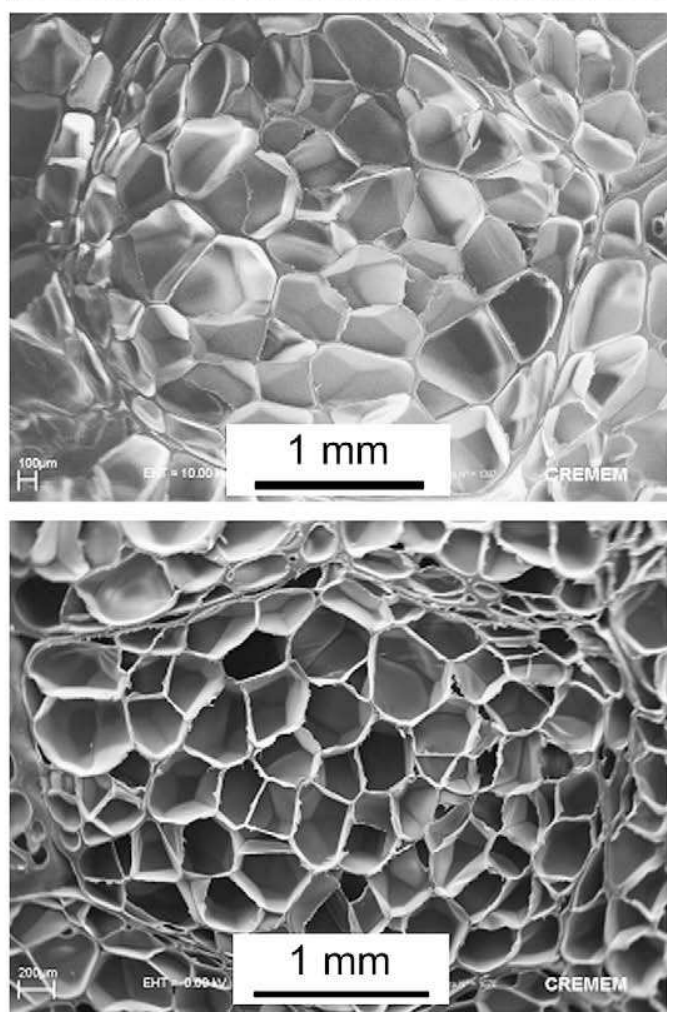

Fig. 3. SEM micrographs of the EPP foam microstructure (bead walls in dotted lines): (a) $34 \mathrm{~kg} \mathrm{~m}^{-3}$, (b) $76 \mathrm{~kg} \mathrm{~m}^{-3}$, and (c) $110 \mathrm{~kg} \mathrm{~m}^{-3}$. 

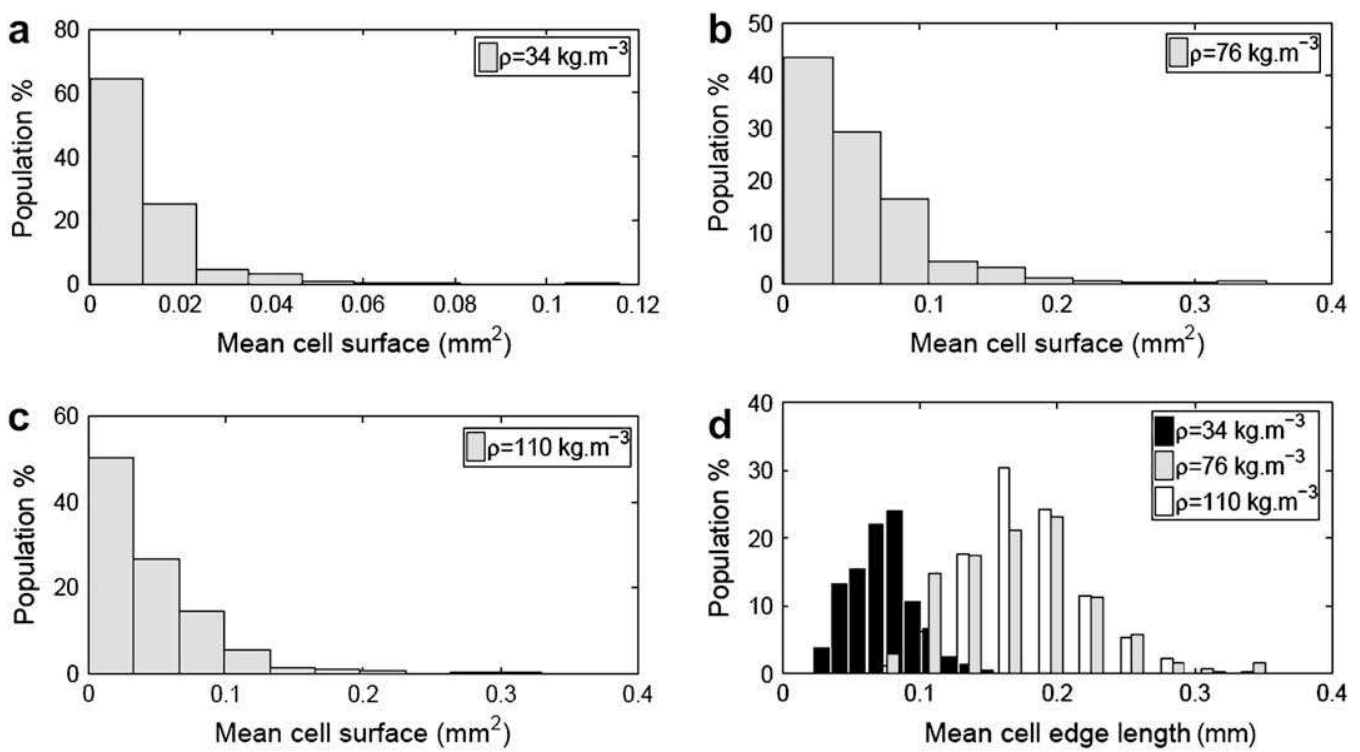

Fig. 4. Measurement of average cell dimensions: (a) cell surface $\rho=34 \mathrm{~kg} \mathrm{~m}^{-3}$, (b) cell surface $\rho=76 \mathrm{~kg} \mathrm{~m}^{-3}$, (c) cell surface $\rho=110 \mathrm{~kg} \mathrm{~m}{ }^{-3}$, and (d) cell edge lengths.

(Fig. 5). As seen in the diagram of the variation of the density in the block foam, the density of specimens extracted from the middle of the block does not show significant variations.

For such a volume the specimens are statistically made of more than 1500 beads and even more closed cells, which is sufficient to consider this volume as an elementary representative volume [25]. For Hopkinson bar tests, cylindrical specimens of $38 \mathrm{~mm}$ in diameter and $10 \mathrm{~mm}$ height are used: the choice of these volume specimens will be discussed in Section 2.4. According to these observations, it could also be assumed that the random organisation of beads and cells in a tangle of the foam structure does not present any particular orientation at meso (beads) or microscopic (cells) scales. The hypothesis of an isotropic foam behaviour has been considered and checked through preliminary compressions tests [26].

Six foam densities are then carefully computed after weight and volume measurements and their values are $34^{ \pm 2} ; 51^{ \pm 2} ; 76^{ \pm 2} ; 87^{ \pm 3}$; $110^{ \pm 4}$; and $150^{ \pm 4} \mathrm{~kg} \mathrm{~m}^{-3}$. They have been tested in quasi-static and dynamic loadings and over a large range of strain rates.

\subsection{Quasi-static experiments}

Quasi-static compression tests were performed using an electromechanical device. In order to identify the mechanical behaviour of foams of each density, five compression tests were carried out at engineering strain rates of 0.01 and $1 \mathrm{~s}^{-1}$. The engineering stress $\sigma=F / S_{0}$ and true strain $e=\ln \left(1+\Delta l / l_{0}\right)$ have been chosen to represent the foam behaviour for two principal reasons: concerning the stress for this material, the variation of the section is not perceptible (the Poisson ratio is close to zero) therefore the real stress $\sigma=F / S$ is close to $F / S_{0}$; secondly, since the foam undergoes a large range of deformation, the strain definition of $e=\ln (1+\Delta l)$ $l_{0}$ ) is more appropriate. Whatever the relevance of this true strain, we have nevertheless considered the time derivative of the engineering strain $\varepsilon=\Delta l / l_{0}$ for measuring the strain rate. Strictly speaking, it is not an objective parameter, but it is not possible to continuously adjust the cross-head speed in order to control the true strain rate. Indeed such an engineering strain rate remains a suitable experimental parameter. The same prevails for dynamic
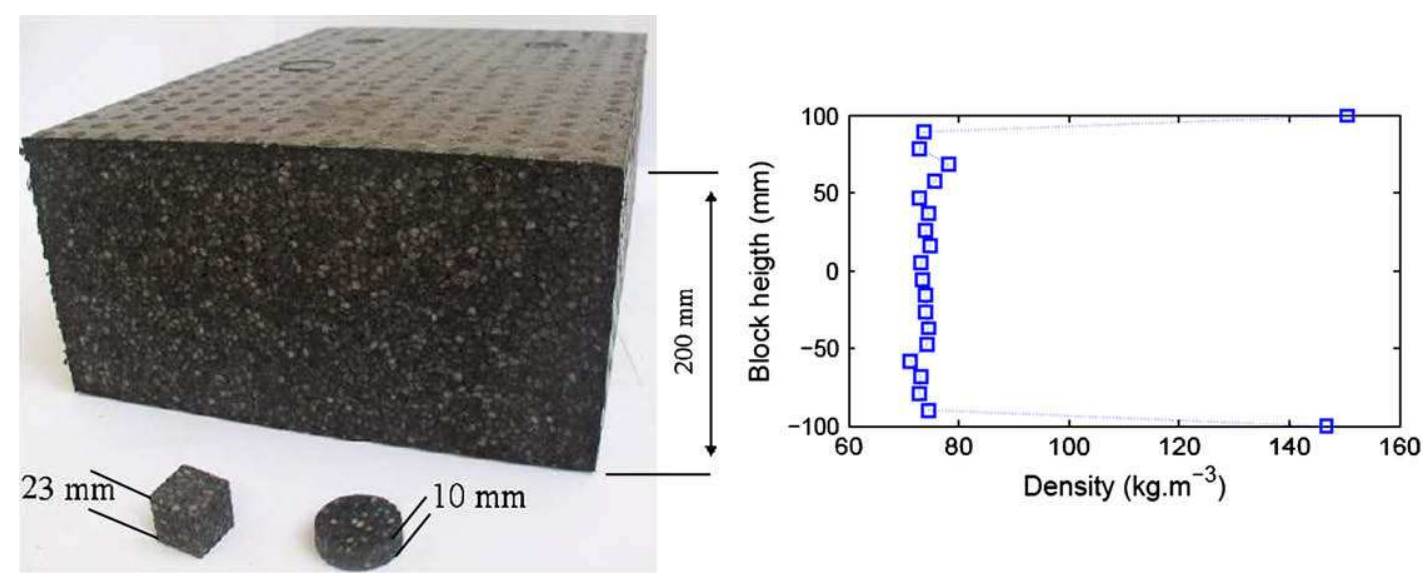

Fig. 5. Foam block, cubic and cylindrical specimens. 


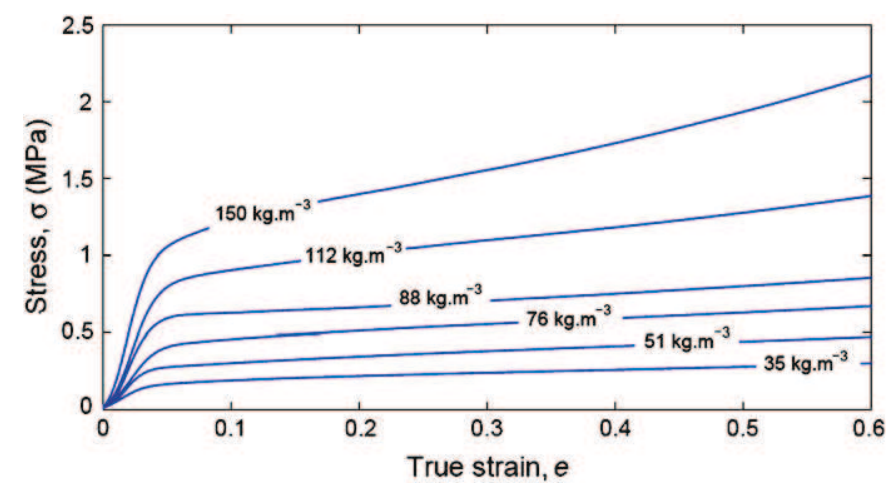

Fig. 6. Quasi-static compressive stress-strain curves of EPP foams at about $0.01 \mathrm{~s}^{-1}$.

experiments with the flywheel and the SHPB technique. Using this convention, the compression responses of these different foams are shown in Fig. 6. To simplify the figure, only one response of each foam density for a strain rate of $0.01 \mathrm{~s}^{-1}$ is plotted and further analysis of all results will be taken into account and presented in Section 3. These quasi-static compression results are representative of the expected classical cellular material behaviour. All tested foams demonstrate an elastic and plateau stress phase which increase in function of the foam density.

\subsection{Intermediate strain rate compression}

The flywheel is an original device (Fig. 7) which makes it possible to dynamically load specimens at intermediate strain rates (from 50 to $800 \mathrm{~s}^{-1}$ ). Again we adopt the same definition for the strain rate: $\dot{\varepsilon}=\mathrm{d} / \mathrm{d} t\left(\Delta l / l_{0}\right)$. This device, due to its high moment of inertia $\left(77 \mathrm{~kg} \mathrm{~m}^{2}\right)$, allows the compression of specimens under constant velocity, since the specimen does not absorb enough energy to slow the wheel down as for EPP foams. A heavy metallic wheel of $617 \mathrm{~kg}$ is run and its rotation velocity is accurately controlled by an asynchronous motor. The hammer which is carried by a wheel measuring $1 \mathrm{~m}$ in diameter makes it possible to load the specimen in tension or compression according to the associated apparatus being used (on the left side of the wheel) [27].

To carry out compression tests when the desired rotation velocity of the wheel is reached, a pneumatic jack pushes the anvil alongside the wheel which is grabbed by the hammer. Due to the impact lever - which is linked to the apparatus framework through a pivot joint - causes the compression loading. Once the specimen is totally crushed or the compressive force reaches a threshold value, a fuse beam buckles and stops further specimen

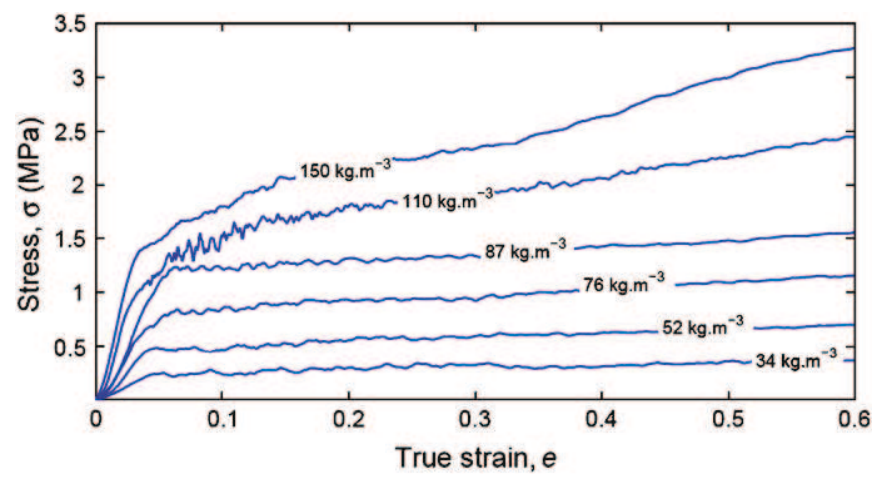

Fig. 8. Intermediate compressive stress-strain curves for EPP foams at about $200 \mathrm{~s}^{-1}$.

compression. The compressive stress is measured by a piezo-electric force sensor and the compression punch displacement is determined by a dynamic laser sensor (Keyence LC 2100) [2]. Preliminary tests have made it possible to check and validate the displacement measurements using a dynamical optical extensometer ZIMMER 200X S/N 201.

As for quasi-static tests the same stress-strain convention is used to obtain the foam compressive behaviour (on this device) at medium strain rates. Fig. 8 shows one of the five tests for each density. These test results are obtained directly from raw signals (without filtering) given by the piezo-electric force sensor and laser displacement sensor and thus they present low disturbances. These disturbances have been investigated and reveal that they are not linked to the foam response. An analysis of the transfer function of the compression device show that these perturbations are linked to the eigenmode of $\sim 3$ and $\sim 6 \mathrm{kHz}$ detected on the stress-strain foam response. As these perturbations do not prevent the identification of the plateau stress modulus in the post-yield plateau region, it has been decided not to filter these signals. These dynamic compression experiments show a constitutive behaviour, which is very similar to the quasi-static stress-strain curves, except for the stress levels which are higher.

\subsection{Dynamic experiments}

To carry out compression tests with Hopkinson bars, the test specimen has to be placed between two slender bars. A projectile strikes the free face of the input bar and the stress wave generated by the impact allows the loading of the specimen at high velocities (Fig. 9).

The behaviour of the specimen is then computed using the strain history generated by the stress waves in the input and output
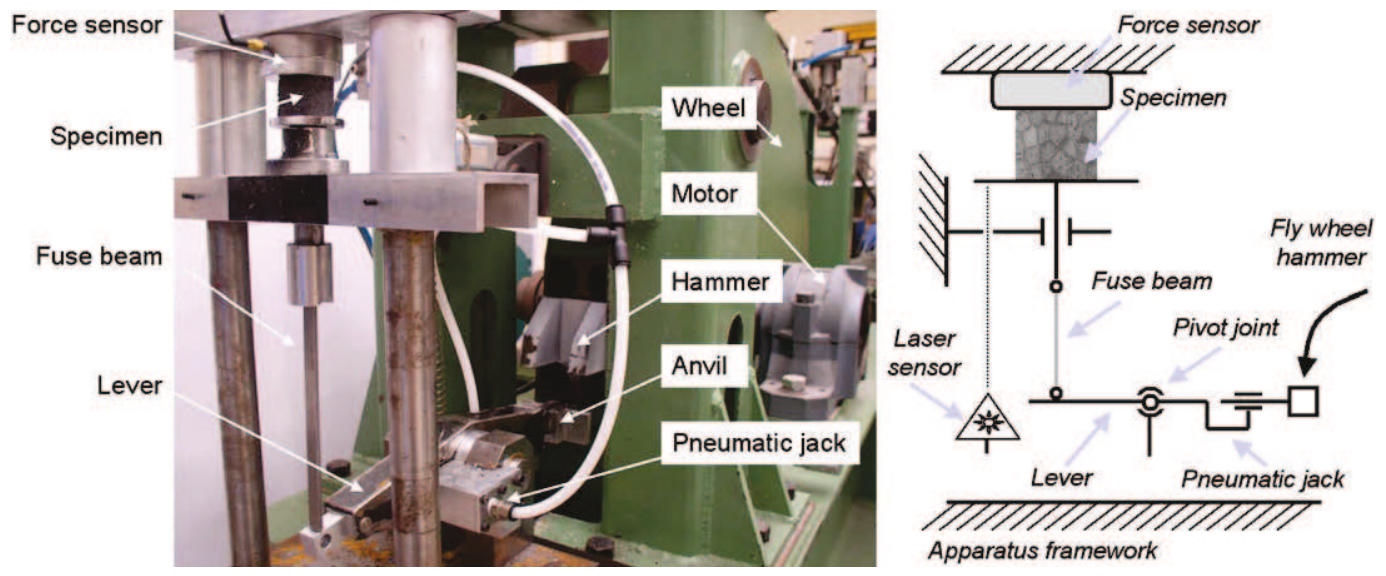

Fig. 7. Compression device of the flywheel. 


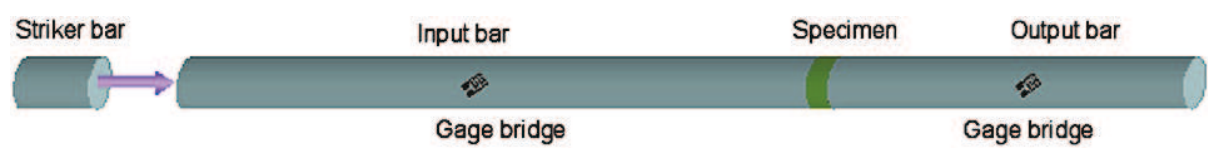

Fig. 9. A schematic of the Split Hopkinson Pressure Bar.

bars. If the tested material is too compliant such as in the case of polymeric foams, the accuracy of the measurement suffers from limitations on the maximum achievable strain in the output bar and the high noise to signal ratio even with semi-conductor gages. Acoustic impedance of usual metallic bars is too high for proper identification of the behaviour of the soft cellular materials. Therefore, these ordinary bars must be adapted using hollow bars or ones of lower impedance $[17,28,19,16]$. Acoustic impedance $Z$ of different materials are compared with an EPP foam of $150 \mathrm{~kg} \mathrm{~m}^{-3}$ in Table 1.

A better match of the acoustic impedance between the bars and the specimens can be reached with Nylon PA6 which ensures the best measurement of signal gage accuracy. Amongst other choices, nylon bars are chosen due to their higher yield stress in comparison to PMMA, thus allowing a higher maximum stress level in the bars. However, such soft viscoelastic bars imply an acoustic dispersion of wave propagation $[29,28]$ as a function of frequency. Accurate knowledge of this phenomenon or the use of velocity gages fixed on the bar-specimen interfaces (which is not investigated here $[30,31])$, is essential to achieve more accurate numerical processing of these waves from the strain gage measurements to the specimen/bar interfaces. An analytical three-dimensional solution of the longitudinal wave propagation in SHPB [32] can be calculated. However, this method is not direct due to the necessity of assuming a general form of the constitutive relationship of the bar's material (for instance the complex Young modulus and the complex Poisson's ratio in the frame of linear viscoelasticity [33]). Therefore, in order to take into account the effects of dispersion and attenuation (acoustic and geometric) an original method proposed by Bacon $[34,35]$ is used. Based on the general quadrupole approach (i.e. the use of a $2 \times 2$ matrix transfer function linking - in our case - two state vectors such as $<$ velocity/force $>$ and $<$ incident wave/reflected wave $>$ according to Eq. (2); see also Appendix) this method consists in measuring experimentally the propagation coefficient $\gamma(\omega)$ of each bar (Eq. (1)) as a function of the wave attenuation $\alpha(\omega)$ and wave phase velocity $c(\omega)$ with the angular frequency $\omega=2 \pi f$.

$\gamma(\omega)=\alpha(\omega)+i \frac{\omega}{c(\omega)}$

One-dimensional viscoelastic analysis in the Fourier domain of the propagation of the measured incident $\tilde{P}$ and reflected $\tilde{N}$ waves in the bars leads to the Eq. (2). These equations make it possible to determine the particle velocity $\tilde{v}$ and force $\tilde{F}$ at any cross section $x$ of the bar according to the propagation coefficient $\gamma$.

$\left\{\begin{array}{c}\tilde{\nu}(x, \omega)=-\frac{i \omega}{\gamma}\left[\tilde{P}(\omega) e^{-\gamma x}+\tilde{N}(\omega) e^{+\gamma x}\right] \\ \tilde{F}(x, \omega)=-\frac{A \rho \omega^{2}}{\gamma^{2}}\left[\tilde{P}(\omega) e^{-\gamma x}+\tilde{N}(\omega) e^{+\gamma x}\right]\end{array}\right.$

Details of this analysis are presented in Appendix.

Table 1

Comparison of impedance materials with EPP foam

\begin{tabular}{lrcc}
\hline & $E(\mathrm{MPa})$ & $\rho\left(\mathrm{kg} \mathrm{m}^{-3}\right)$ & $Z=\rho c\left(\mathrm{~kg} \mathrm{~s}^{-1} \mathrm{~m}^{-2}\right)$ \\
\hline Steel 18-10 & 203,000 & 7900 & $4 \times 10^{7}$ \\
Aluminium AU4 G & 75,000 & 2800 & $1.4 \times 10^{7}$ \\
Magnesium & 46,000 & 1740 & $8.9 \times 10^{6}$ \\
Plexiglas PMMA & 2900 & 1800 & $2.2 \times 10^{6}$ \\
Nylon PA6 & 3300 & 1140 & $1.9 \times 10^{6}$ \\
EPP foam & 27 & 150 & $6.3 \times 10^{4}$ \\
\hline
\end{tabular}

\subsubsection{Determination of the propagation coefficient, experimental set-up}

To evaluate the propagation coefficient at the highest signal frequency, the stress wave must be as short as possible. Therefore a spherical steel bullet of $10 \mathrm{~mm}$ in diameter was used as a projectile. The bars of $40 \mathrm{~mm}$ in diameter (denoted $D$ ) are made of Nylon PA6 with a density of $1140 \mathrm{~kg} \mathrm{~m}^{-3}$ and the first axial frequency is around $50 \mathrm{~Hz}$. The transient wave propagation theory is then valid. The position of the first strain gage bridge is $1604 \mathrm{~mm}$ from the specimen on the $3106 \mathrm{~mm}$ long input bar. The second strain gage bridge is $540 \mathrm{~mm}$ from the specimen on the $3103 \mathrm{~mm}$ long output bar.

The strain gage voltage signal was measured at $200 \mathrm{kHz}$ on the input bar (Fig. 10). The experimental results of the attenuation coefficient and phase velocity were plotted in Fig. 11 versus frequency. It can be noticed that the attenuation coefficient increases as the frequency increases. The phase velocity is close to the phase velocity in the case of one-dimensional elastic wave propagation $\left(c=\sqrt{E / \rho}=1700 \mathrm{~ms}^{-1}\right)$ for low frequencies $(<8 \mathrm{kHz})$. The celerity of high frequency waves then decreases as a consequence of the geometric effects. Indeed when the wavelength $\lambda$ gets the same order of magnitude like the lateral dimension of the bar, radial inertia effects are more significant. For instance, at $0.4 \mathrm{kHz}$, the wavelength is about $400 \mathrm{~mm}$, which is 10 times the bar diameter $D$ value $(40 \mathrm{~mm})$. On the other hand at $13 \mathrm{kHz}$, the wavelength is about $120 \mathrm{~mm}$, which is no longer consistent with the onedimensional approach: $\lambda / D \sim 3 \ll 10$. In this case the ChreePochhammer oscillations become significant $[36,37]$.

\subsubsection{Specimens and experimental assumptions}

In order to do SHPB tests in good conditions it must be assumed that specimens are under stress equilibrium during the whole test $[38,39]$. This equilibrium is reached after an initial ringing-up period which has to be as short as possible: this period is dependant on the wave velocity within the specimen. Consequently, the stiffer the specimen, the shorter this period. Many researchers agree that this stress state equilibrium requires at least three or four wave reverberations in the specimen [40] and often do not rely on the early measurement which often invalidates the elastic modulus measurement [31,41]. However, Zhao and Gary [5] have shown that it is possible to determine the behaviour of non-metallic materials such as polymers in the range of small strains taking into account the propagation in the specimen. Of course this method is only

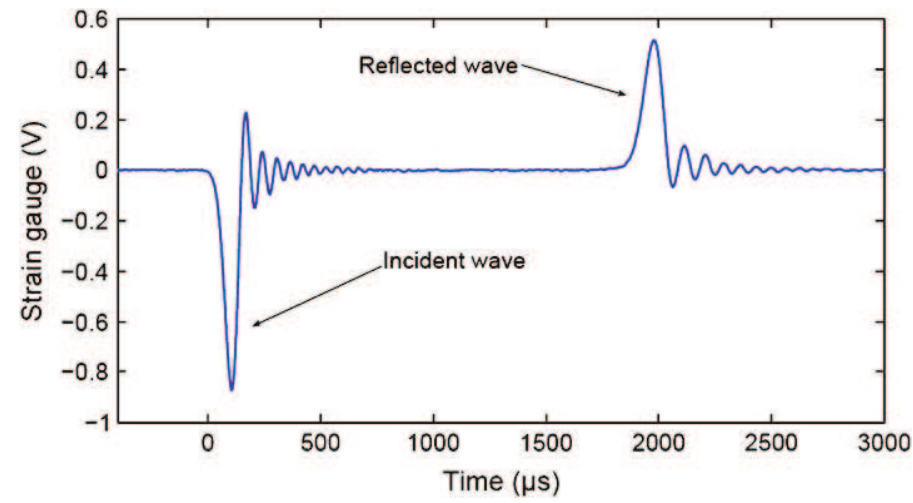

Fig. 10. Strain gage voltage signal generated by the spherical bullet impact. 

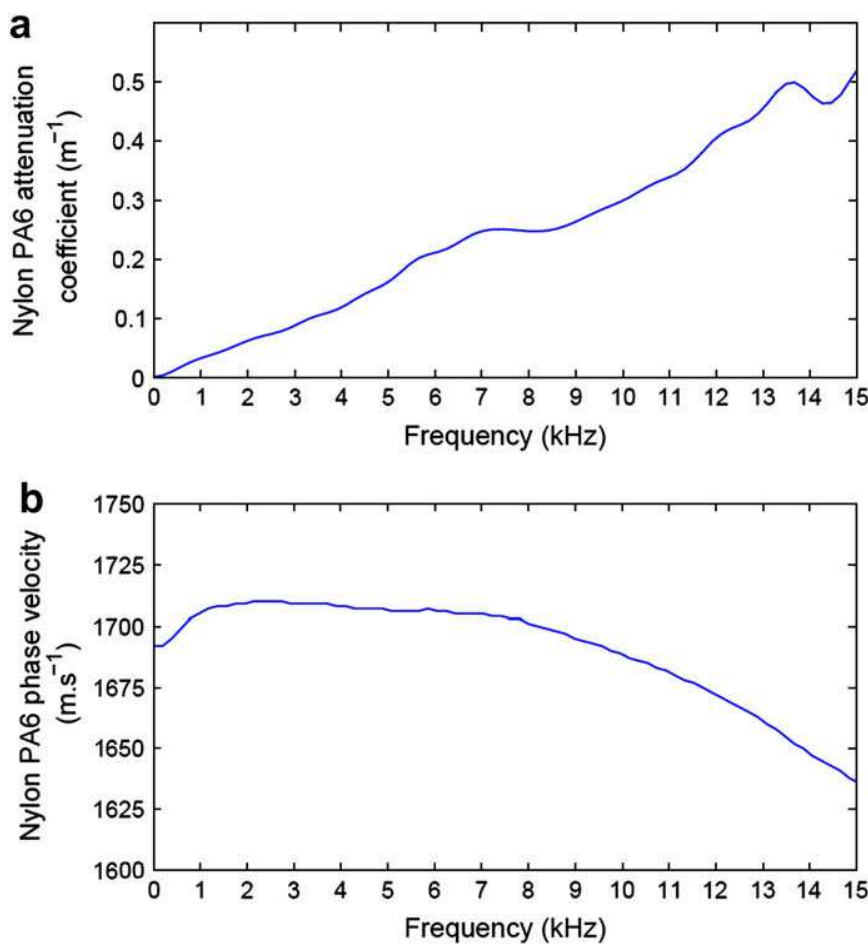

Fig. 11. Experimental attenuation coefficient (a) and phase velocity (b) for Nylon PA6 bar.

consistent when the behaviour of the specimen is homogeneous; in the case of local instabilities crushing or shear bending, it fails. One solution thus consists in reducing the thickness of the specimen which restricts the propagation time. Hence the specimen height cannot be as high as that of quasi-static or intermediate tests. Zhao [42] has shown that the effect of the specimen height on the material behaviour is mainly due to its radial inertia and friction considerations (three-dimensional effects).
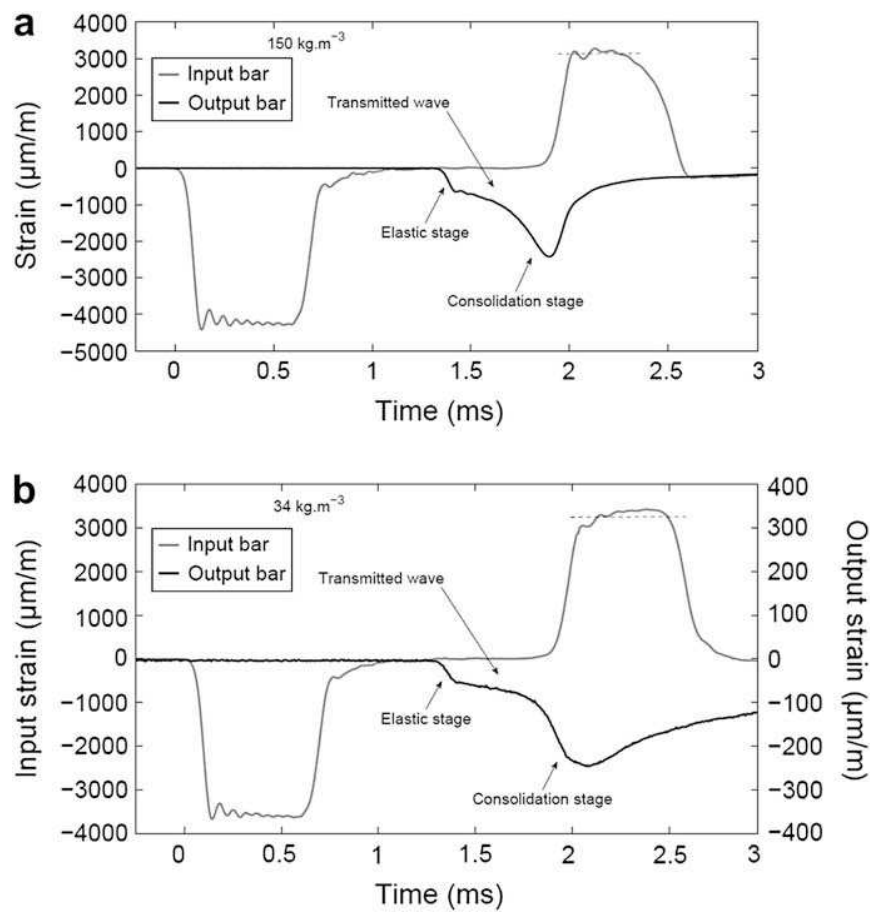

Fig. 12. Stress waves monitored during SHPB tests on a foam of: (a) $150 \mathrm{~kg} \mathrm{~m}^{-3}$, and (b) $34 \mathrm{~kg} \mathrm{~m}^{-3}$.
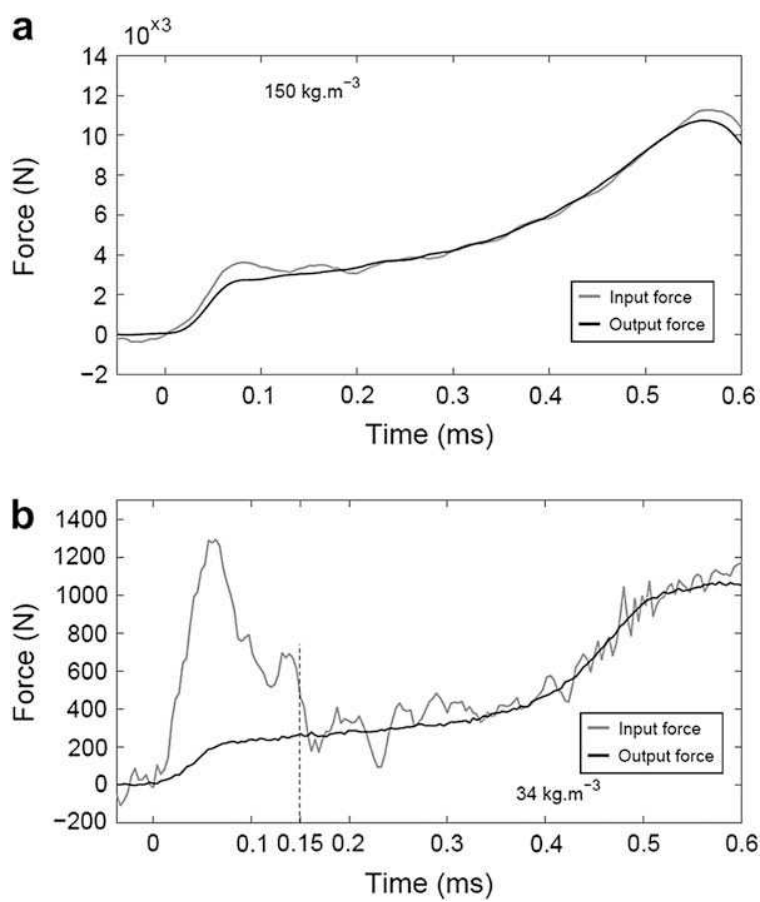

Fig. 13. Force history at the front and back faces of the foam specimen during SHPB tests: (a) $150 \mathrm{~kg} \mathrm{~m}^{-3}$, and (b) $34 \mathrm{~kg} \mathrm{~m}^{-3}$.

In our case, specimen height could have been shortened since Poisson's ratio of the foam is close to zero and frictional effects are limited by using lubricants at the bar/specimen interfaces. Finally, a height of $10 \mathrm{~mm}$ was chosen in order to validate SHPB assumptions and to be high enough according to the bead dimensions and the damage mechanisms. SHPB of $40 \mathrm{~mm}$ in diameter was then assembled in order to guarantee the same elementary representative volume of cubic specimens as designed for quasi-static tests. The $38 \mathrm{~mm}$ diameter of the SHPB specimens makes it possible to obtain an elementary representative volume less than $5 \%$ lower than those of cubic specimens (Fig. 5). They also make it possible to still assume this volume as representative since the foam failure mode which appears during dynamic tests is very localised in bands perpendicular to the loading [2], such as the progressive collapse in metal foams [43]. When all are said and done, this specimen geometry makes for a satisfactory compromise even when considering the loading characteristics of the sample.

Examples of stress waves monitored during SHPB tests for the two extreme densities ( 150 and $34 \mathrm{~kg} \mathrm{~m}^{-3}$ ) are shown in Fig. 12 as a function of time. Force histories at the front and back faces of the foam specimens are then derived using the one-dimensional

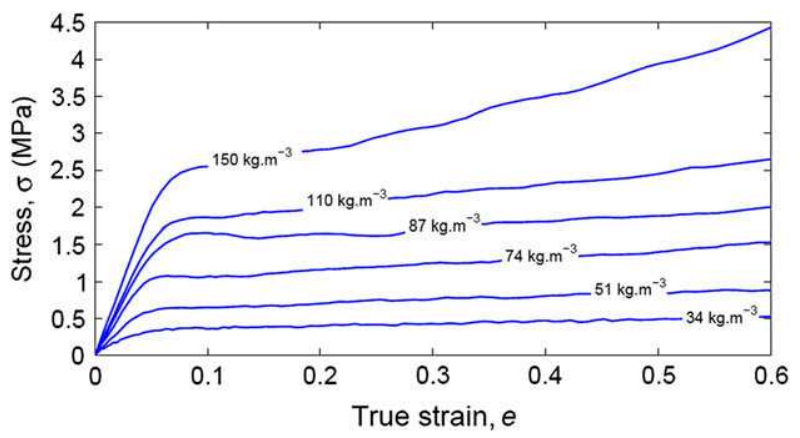

Fig. 14. Dynamic compressive stress-strain curves for EPP foams at about $1500 \mathrm{~s}^{-1}$. 


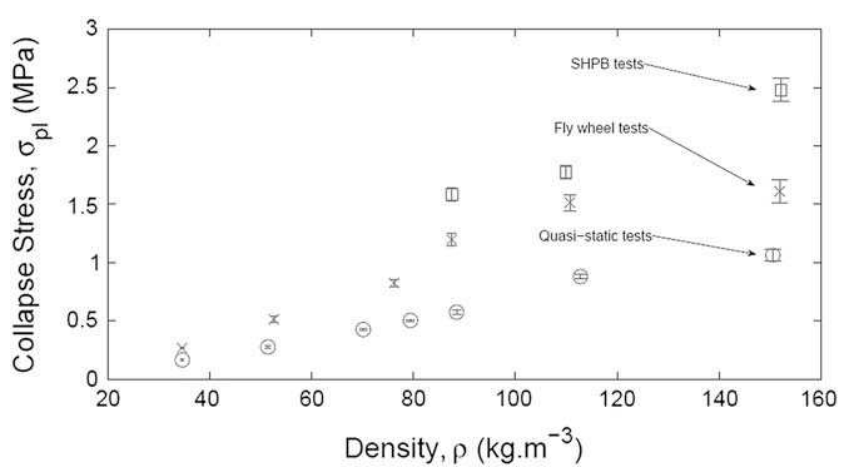

Fig. 15. Variation of collapse stress as a function of foam density.

viscoelastic analysis (Fig. 13). The different compression stages clearly appear, which means that the output force signals are reliable to some extent which have to be assessed: in the case of the high density $\left(150 \mathrm{~kg} \mathrm{~m}^{-3}\right)$, the equilibrium criterion is satisfied overall (because of the wave velocity), whereas in the case of low density foam $\left(34 \mathrm{~kg} \mathrm{~m}^{-3}\right)$ there is a transient period of about $0.15 \mathrm{~ms}$. Therefore the plateau stress values are evaluated above $10 \%$ of strain corresponding to $0.15 \mathrm{~ms}$ since the engineering strain rate is then $1500 \mathrm{~s}^{-1}$. Similar situations occur for densities below $78 \mathrm{~kg} \mathrm{~m}^{-3}$ so that the so-called collapse stress in the SHPB tests can be evaluated just for densities above $78 \mathrm{~kg} \mathrm{~m}^{-3}$. Moreover it has to be noticed, looking at the reflected waves, that engineering strain rates $\dot{\varepsilon}=\mathrm{d} / \mathrm{d} t\left(\Delta l / l_{0}\right)$ are approximately constant.

Consequently the foam behaviour will be represented by a "onewave" analysis [15] considering as usual that specimen stress is directly proportional to the transmitted wave.

Then, as the specimen and bar dimensions have been chosen in order to satisfy at best these assumptions, SHPB tests could have been performed in the best conditions. In order to limit dispersion due to dynamic measurements and accurately present the high strain rate foam behaviour, tests on foams of each density foam were repeated 10 times. Typical stress-strain curves representing each foam density are plotted in Fig. 14.

The foam behaviour at high strain rates close to $\dot{\varepsilon}=1500 \mathrm{~s}^{-1}$, shows the same typical cellular material behaviour as those obtained at quasi-static or intermediate loading velocities. However, as the strain rate increases, both collapse and plateau stress increase which highlights the strain rate sensitivity on the foam compression response. The plateau region is nearly horizontal for low density foams (34 and $51 \mathrm{~kg} \mathrm{~m}^{-3}$ ), increases as density increases and shows a high slope for the highest density $\left(150 \mathrm{~kg} \mathrm{~m}^{-3}\right)$.

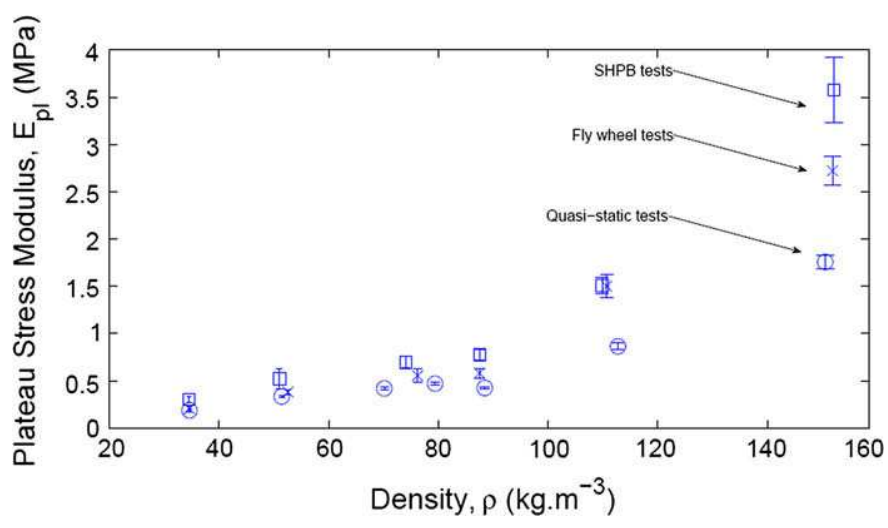

Fig. 16. Variation of plateau stress modulus as a function of foam density.

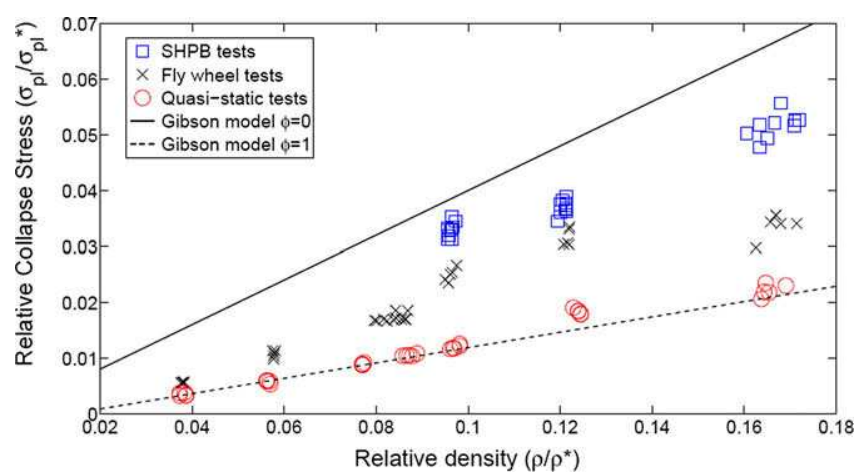

Fig. 17. Relative collapse stress versus relative density for quasi-static, intermediate and dynamic loadings.

\section{Analysis of results}

To assess the contribution of the foam density and the strain rate, parameters of collapse stress $\sigma_{\mathrm{pl}}$ and plateau stress modulus $E_{\mathrm{pl}}$ are identified from the experimental results. The plateau stress modulus is identified as the slope of the quasi-plateau region of the stress-strain foam behaviour (from $e=0.1$ to $e=0.5$ ). The intersection of the tangents of this plateau stress region and the elastic region was used to determine the collapse stress. In order to accurately identify these parameters on the more than 150 specimens tested, an optimization loop was driven by the optimization package of ZeBuloN software [44].

\subsection{Effect of foam density}

To represent the density effect on the foam behaviour, each test carried out at quasi-static loading at strain rates of $0.01 \mathrm{~s}^{-1}$ and dynamic tests at strain rates of 200 and $1500 \mathrm{~s}^{-1}$ allow us to compute mean values associated with their standard deviations for each density.

The collapse stress $\sigma_{\mathrm{pl}}$ variation as a function of the foam density is plotted in Fig. 15 for each loading velocity. The variation of this parameter seems to be linear for low densities from 34 up to $76 \mathrm{~kg} \mathrm{~m}^{-3}$, whether under quasi-static or dynamic loadings. However, for high densities above $87 \mathrm{~kg} \mathrm{~m}^{-3}$ at dynamic loadings (flywheel and SHPB tests) the foam behaviour changes. The variation of the collapse stress is less significant for higher densities.

Concerning the variation of the plateau stress modulus $E_{\mathrm{pl}}$ plotted in Fig. 16, its variation seems to be affected more noticeably for high densities $\left(150 \mathrm{~kg} \mathrm{~m}^{-3}\right)$ than for low densities. This variation rises exponentially with density as for quasi-static, intermediate or dynamic loadings.

Experimental results can be compared with the analytical model for closed cell foams proposed by Gibson and Ashby. The Gibson and Ashby law is a micro-mechanical model which considers the deformation mechanisms of the micro-cell structure under loading [20]. The following equation relates to the collapse stress evolution as a function of the relative density:

$\frac{\sigma_{\mathrm{pl}}}{\sigma_{\mathrm{pl}}^{*}} \approx 0.3\left(\phi \frac{\rho}{\rho^{*}}\right)^{3 / 2}+0.4(1-\phi)\left(\frac{\rho}{\rho^{*}}\right)$

where $\sigma_{\mathrm{pl}}$ is the collapse stress of the foam, $\sigma_{\mathrm{pl}}{ }^{*}$ the collapse stress of the solid material, $\varphi$ the volume fraction of cell edges in a unit volume and $(1-\phi)$ the remaining fraction of the solid contained in the cell faces, $\rho$ the density of the foam and $\rho^{*}$ the density of the solid material. The values of the collapse stress $\sigma_{\mathrm{pl}}{ }^{*}$ and the density 
$\rho^{*}$ of the solid material are given by literature to be $48 \mathrm{MPa}$ and $910 \mathrm{~kg} \mathrm{~m}^{-3}$, respectively [20]. The first term of this Eq. (3) denotes the plastic buckling and bending of the cell edges, and the linear term the compression and stretching of the cell faces. The variation of the collapse stress of the present foams is shown in Fig. 17 as a function of relative density for quasi-static, intermediate and dynamic loadings.

From Eq. (3), the upper and lower limits of the relative collapse stress can be drawn in this Fig. 17 by changing $\varphi$. The data of quasistatic tests lie close to $\phi \approx 1$ : this suggests that cells deform primarily through the bending of the cell edges. A reason for this would be that the cell faces may have ruptured before plastic collapse of the cell edges. According to Gibson and Ashby, the contribution of the cell faces is comparatively small and negligible as they are often damaged before the cell edges. The relative collapse stress at high strain rate exhibits a higher value than that at low strain rate especially for high relative density $\left(\rho / \rho^{*}>0.1\right)$ and comes closer to the line of $\varphi=0$. This apparent increase in the strain rate sensitivity suggests that contribution of the cell faces to the foam enhancement becomes more important when cell faces are thicker: not because of their own deformation mechanisms but especially because of inertia effects and that they allow gas to be trapped in the cells. Indeed, even for these high relative densities $\left(\rho / \rho^{*}>0.1\right)$ quasi-static data lie close to $\phi \approx 1$. Further investigations are under way to clarify the gas pressure effect such as the first one in Section 3.4 and the evolution of the relative plateau stress modulus versus relative density.

\subsection{Effect of strain rate}

Quasi-static and dynamic tests are plotted in Figs. 18 and 19. It can be noticed on Fig. 18 (representing the variation the collapse stress $\sigma_{\mathrm{pl}}$ as a function of the logarithm of strain rate), that foam behaviour shows an increase of strength when the strain rate increases. According to the foam density, one can note that this variation is not the same. A slight rise of strength could be observed for low density foams $\left(34,51\right.$ and $\left.76 \mathrm{~kg} \mathrm{~m}^{-3}\right)$ whereas denser foams seem to be more influenced. The results present two distinct variation regimes according to strain rate. A quasi linear response between the logarithm of strain rate and collapse stress up to $200 \mathrm{~s}^{-1}$ for each foam density matches experimental results. This slope increases with foam density, and then collapse stress exhibits a significant increase in rate sensitivity. In our study we have not investigated the accurate value of the threshold strain rate.

The same conclusions can be made for the plateau stress modulus $E_{\mathrm{pl}}$ as for collapse stress $\sigma_{\mathrm{pl}}$ variation. But it seems that the strain rate effect reduces for all density foams except for the most dense one. This figure also reveals that the high density effect on the foam behaviour as in Fig. 16, is less pronounced for low density foams (from 34 to $87 \mathrm{~kg} \mathrm{~m}^{-3}$ ).

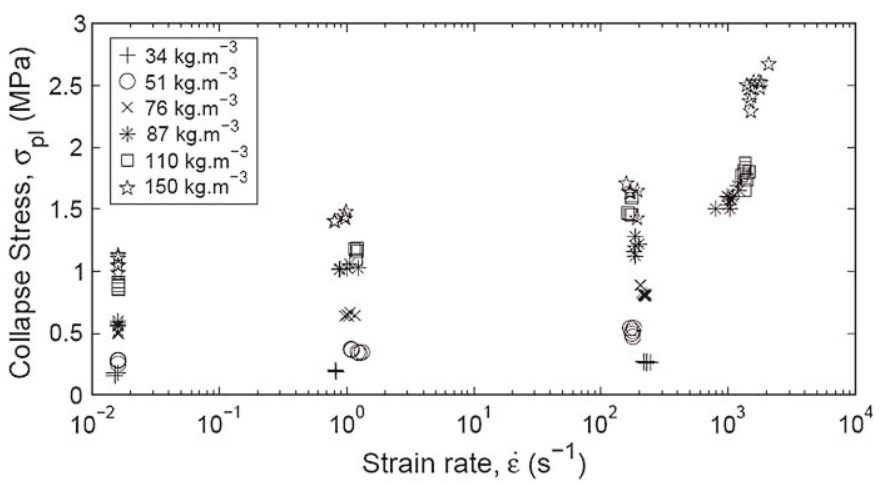

Fig. 18. Collapse stress as a function of the strain rate for different foam densities.

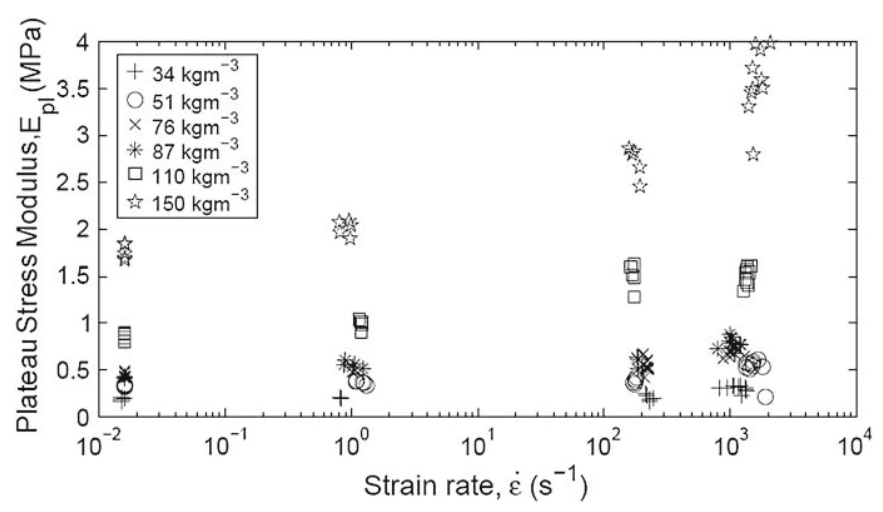

Fig. 19. Plateau stress modulus as a function of the strain rate for different foam densities.

This foam strain rate sensitivity on the collapse stress and the plateau stress modulus could be linked to the viscoelastic behaviour of the solid polypropylene of the cell and bead walls to its microstructure and the entrapped gas in the closed-cells.

\subsection{Effect of microstructure}

From these macroscopic observations the deformation field can be considered closely linked to the foam microstructure at least in terms of cell size. Therefore two EPP foams with equal density of $90 \mathrm{~kg} \mathrm{~m}^{-3}$ but with different microstructures are investigated. Stress-strain curves from these two EPP foam microstructures (EPP foam A and B) are shown in Fig. 20 for quasi-static, intermediate and dynamic loadings. The EPP foam A corresponds to the industrial foam tested in the first part of this article and the EPP foam $B$ corresponds to another industrial foam which presents the same particular double scale (beads and closed cells) but with smaller cell sizes (Fig. 21). Careful observations and analysis carried out using the same method as for the EPP foam A reveal that $60 \%$ of EPP foam B cells are about 10 times smaller.

Both foams have the same stress-strain behaviour: an elastic followed by a plateau stress stage. However, some differences can be noticed. At quasi-static loading the EPP foam B shows a collapse stress twice as high as compared to EPP foam A. Concerning dynamic results the EPP foam B does not show a post collapse softening transition but a larger increase in the plateau stress modulus could be noticed in contrary to the EPP foam A. From these experimental results, it could be noticed that EPP foam A is more sensitive to strain rate and EPP foam B presents a greater strength.

It is known that smaller cell sizes are less prone to buckling which results in a higher collapse stress level and larger and thicker cell wall sizes are more susceptible to the micro-inertia effect.

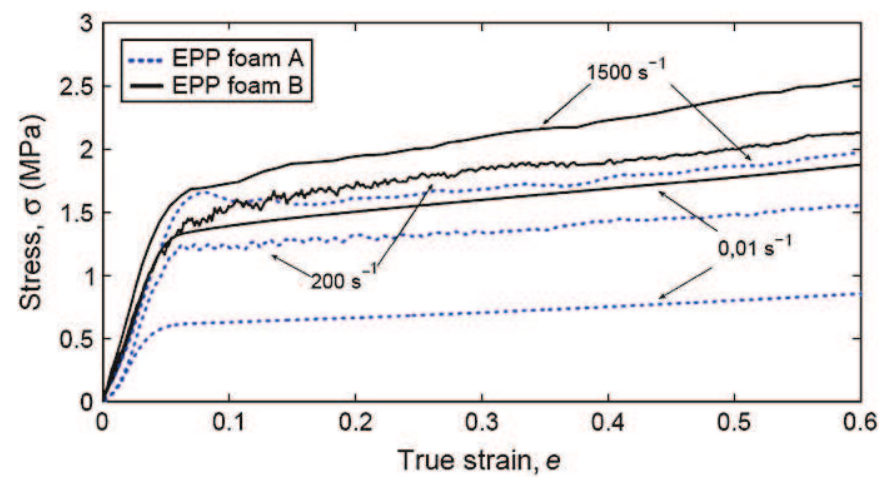

Fig. 20. Stress-strain curves for two different EPP foam microstructures. 

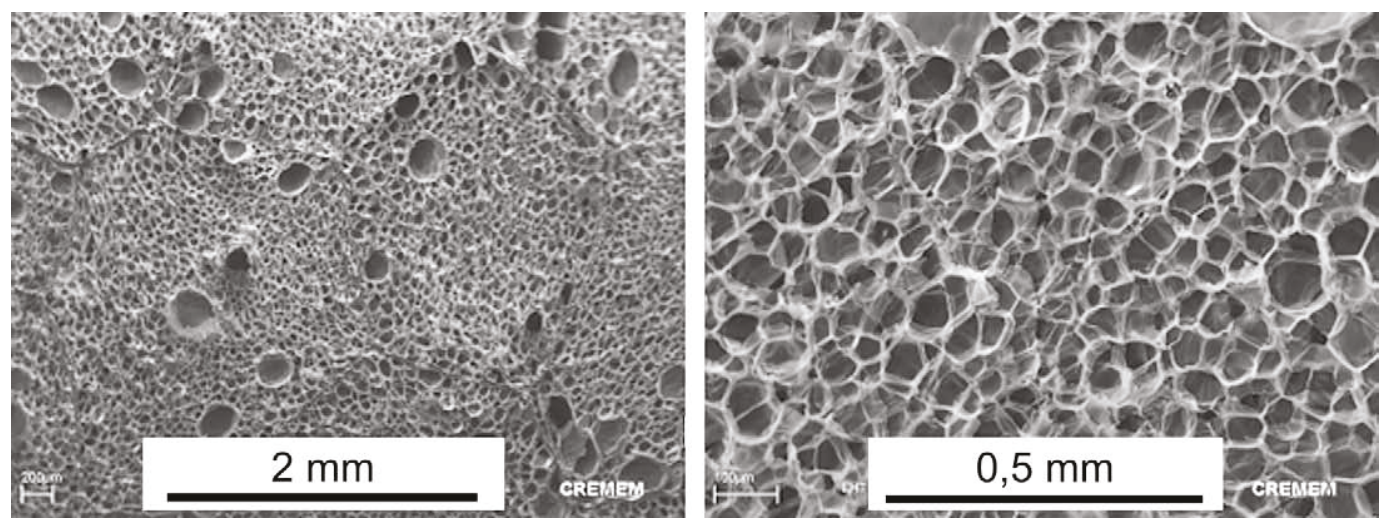

Fig. 21. SEM micrographs of the EPP foam B microstructure, $\rho=90 \mathrm{~kg} \mathrm{~m}^{-3}$.

Micro-inertia effects are greater in the case of dynamic loadings but also when the foam density increases and their cell edges thicken. Tests carried out on specimens of $150 \mathrm{~kg} \mathrm{~m}^{-3}$ in Fig. 19 also reveal this phenomenon by showing that the strain rate sensitivity is not saturated within the observed strain rate range, contrary to other foam densities thanks to micro-inertia effects.

SEM analysis was carried out on a $90 \mathrm{~kg} \mathrm{~m}^{-3}$ specimen in order to focus on the deformation mechanism generated after dynamic loadings. An accurate examination of the expanded morphology (closed-cells and fused beads) of the undeformed specimen was possible thanks to $27 \mathrm{SEM}$ pictures at a $\times 80$ magnification. Fig. $22 \mathrm{a}$ shows a $19.6 \times 10.1 \mathrm{~mm}^{2}$ observation area in which the expansion process has induced non-uniform cell distribution, leaving smaller cells close to the bead boundaries (black lines). This explains the great dispersion cell surface measurement of Fig. 4. Fig. 22b shows the same specimen after a dynamic loading with the viscoelastic SHPB. A global strain of $50 \%$ was imposed and a global residual strain of $12 \%$ was measured. It does not allow us to conclude that the global elastic recovery is $38 \%$ since the deformation is not homogeneous. The elasto-plastic deformation is restricted to some meso volumes, which represent more or less $50 \%$ of the global volume.

a
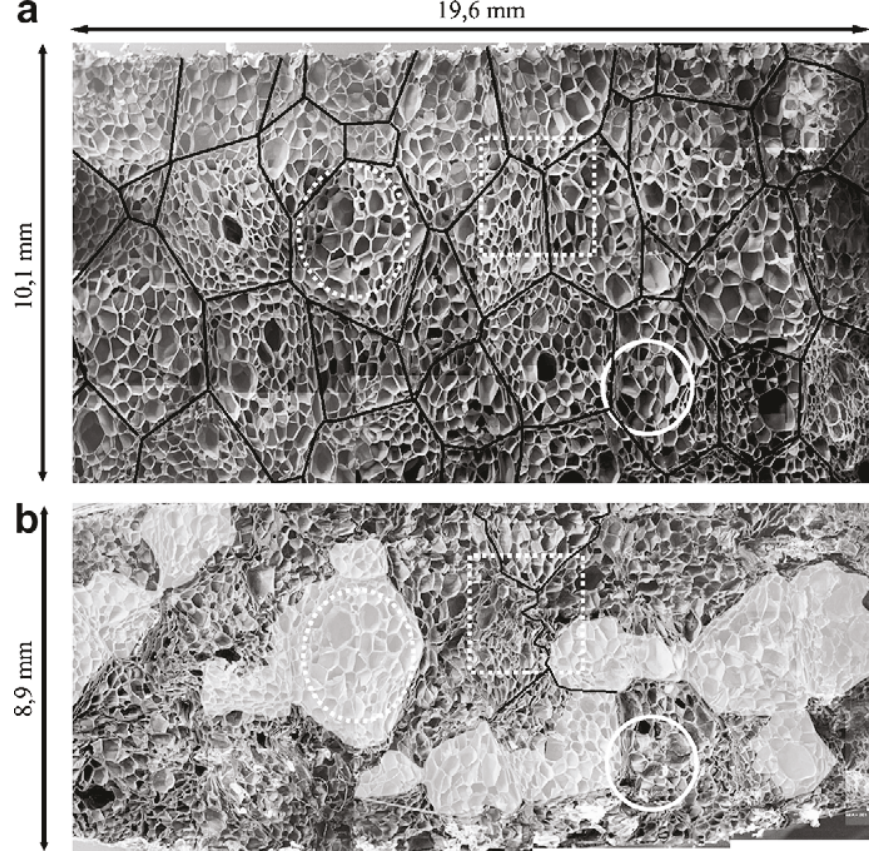

Fig. 22. SEM micrograph of EPP foam $A, \times 80$ magnification: (a) undeformed specimen (bead walls in black lines), and (b) after $50 \%$ of dynamic compression with the SHPB.
It could be observed that different zones of the specimen area are totally undeformed as in the white dotted-line circles on the two pictures whereas other specimen areas are totally crushed like the cells in the solid-line circles. One can also say that some of the bead walls (black lines) in the loading direction are totally buckled such as the area delimited by the white dotted-line rectangles. One can note that cell deformation is mainly linked to the behaviour of the bead walls. In Fig. 22b the pale zones correspond to the undeformed area of the foam and highlight that foam deformation is not uniform and appears bead by bead.

The same SEM analysis on the EPP foam B has been made. In order to visualise the cell deformation more than 80 SEM pictures have been necessary to represent the specimen area of $15.2 \times 7.5 \mathrm{~mm}^{2}$ at a magnification of $\times 256$. Fig. 23 shows that high cell size dispersion (revealed by the SEM investigation in paragraph 2.1 ) is randomly dispersed in the specimen. Similar damage phenomena as for the EPP foam A could be observed: some specimen areas are undeformed such as the one delimited by the white dotted-line circle in contrast to other regions where cells are totally crushed (solid-line circle). Bead walls which are perpendicular to the load direction also contribute to the foam deformation and buckle as in the white rectangle. In Fig. 23b the pale zone defines the undeformed foam area which appears in bands whatever the bead wall geometries are.

a
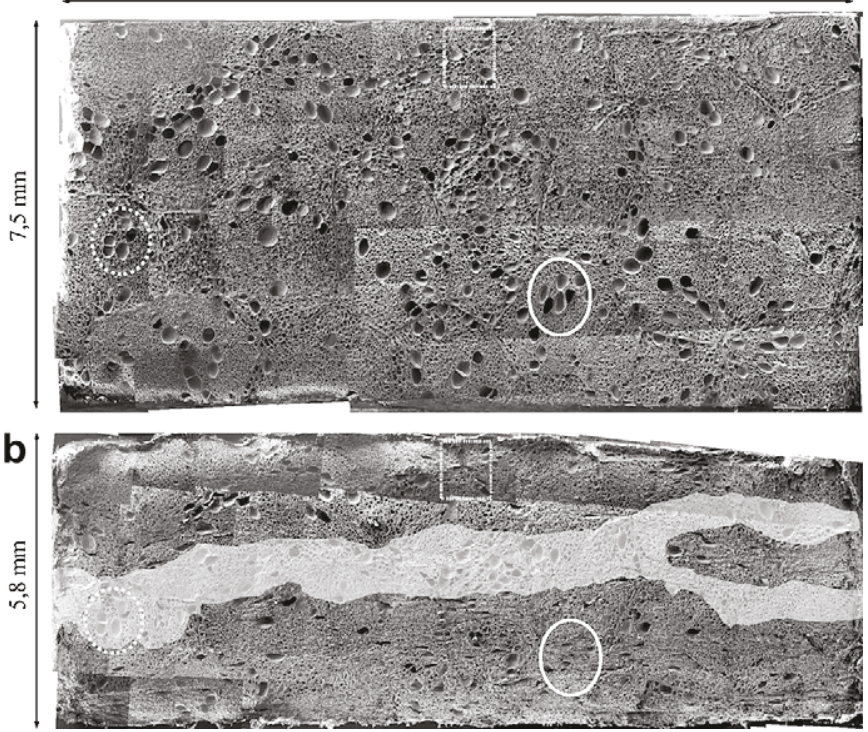

Fig. 23. SEM micrograph of EPP foam $B, \times 256$ magnification: (a) undeformed specimen, and (b) after $50 \%$ of dynamic compression with the SHPB. 


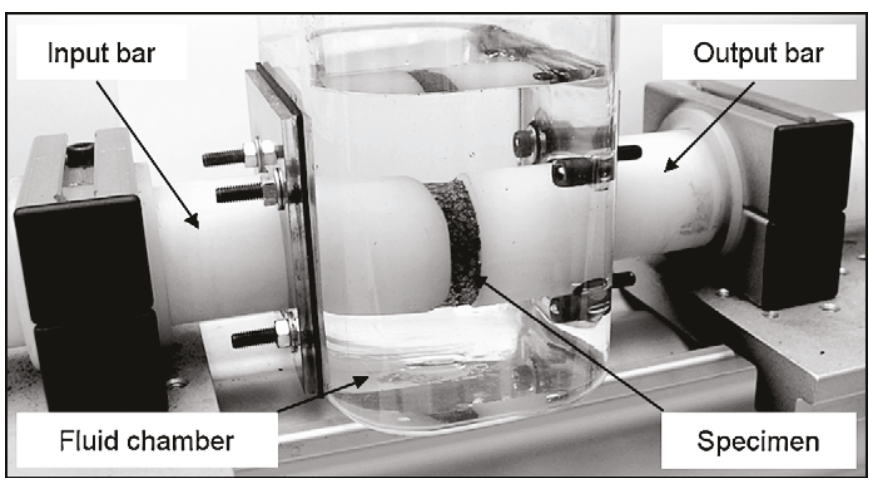

Fig. 24. SHPB compression tests in fluid chamber.

Unfortunately, as these foam materials are of industrial origin, only global manufacturing process is known as details of these processes are under a patent. However, the origin of these different microstructures is certainly a result of the base material (i.e. polymer tacticity, charges, etc.) and foaming technology.

\subsection{Effect of the entrapped gas in closed-cells}

To assess the contribution of the gas within closed cells and to highlight the dynamical hardening phenomenon, compression tests have been performed in water. Compression tests with the SHPB apparatus required the use of a specific water tank presented in Fig. 24, while simple containers filled with water were used for quasi-static and flywheel tests. The following results only show pictures from the tests performed on the EPP foam $B$ but the two microstructure foams ( $A$ and $B$ ) have been investigated and the same conclusions could be drawn.

Pictures of the gas flow during quasi-static tests $\left(\varphi=0.01 \mathrm{~s}^{-1}\right)$ are presented in Fig. 25 showing height stages of the foam deformation until $50 \%$ of strain (from $e=0$ to $e=0.5$ ). These pictures clearly show that gas bubbles squeeze out of the foam right at the beginning of the compression. From the first four pictures, until 10\% of strain, the gas bubbles randomly appear on the foam face and grow slowly. It could be noticed that no gas bubbles are visible on the left side of the foam before the compression starts $(e=0)$. The black dotted-line circle line shows the variation of two bubbles until $e=0.3$ where the gas escapes during the whole deformation process and is carried out in a slow and progressive way. Then these gas bubbles become too large and leave the foam ( $e=0.4$ and $e=0.5$ ). From these observations it is obvious that the contribution of the gas to the compressive stiffness of the foam depends on the deformation rate.

Concerning intermediate strain rate compression at $200 \mathrm{~s}^{-1}$, careful records of the test using a high speed camera FASTCAM-APX $R S 250 k$ at 3000 pps with a resolution of $1024 \times 1024$ pixels make it possible to represent the same height stages of specimen deformation shown in Fig. 26.

From these pictures, one can say that gas bubbles are smaller and do not appear on the first four pictures until $e=0.1$. Then between 10 and $20 \%$ of strain (Fig. 26, $e=0.2$ ) some small gas bubbles appear in the rectangle area delimited by the white dotted lines. Fig. 26, $e=0.3$ this area grows through the specimen where the strain localization is the highest. Then, in Fig. 26, $e=0.4$ and $e=0.5$ the gas bubbles seem to have reached all the foam face except a small area delimited by the white dash lines where the foam doesn't appear to be deformed. It could be noticed that entrapped gas remains for higher strains than during quasi-static tests; therefore it could be considered that gas pressure in closedcells increases significantly and affects the macroscopic foam behaviour.

Pictures of the dynamic test at high strain rate $\left(\varphi=1500 \mathrm{~s}^{-1}\right)$ recorded at 50,000 pps with a resolution of $256 \times 128$ pixels, show that the first gas bubbles appear at $20 \%$ of strain (Fig. 27, $e=0.2$ ). This gas leakage is very localised in a band were the beads are totally crushed (nearly dense), the foam deformation progresses and gas bubbles are still visible in Fig. 27, $e=0.3$. Then the foam deformation becomes more homogeneous in the specimen (Fig. 27, $e=0.4$ ). Due to the high strain rate gas bubbles cannot escape from the foam as they don't have enough time. The gas largely contributes to the dynamic hardening foam behaviour as the gas remains for larger deformations than during intermediate tests. In Fig. 27, $e=0.5$ the strain field in the white dotted-line rectangle becomes
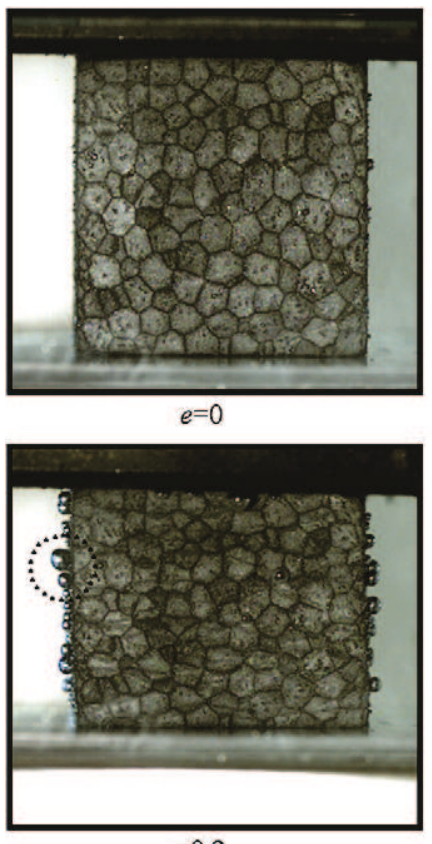

$e=0.2$

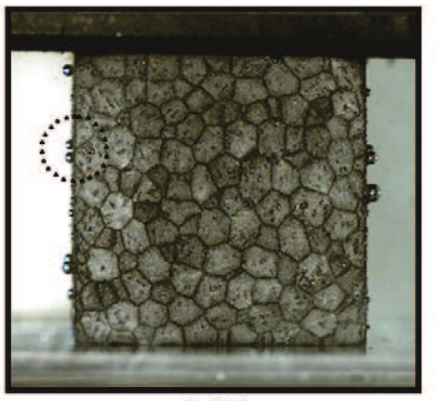

$e=0.025$

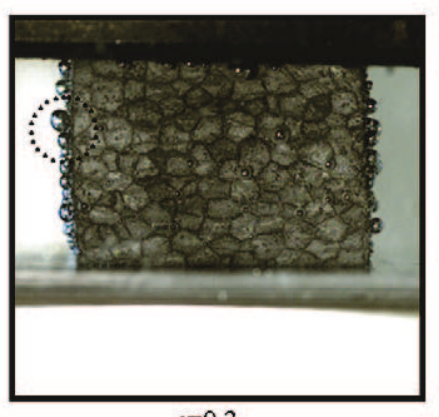

$e=0.3$

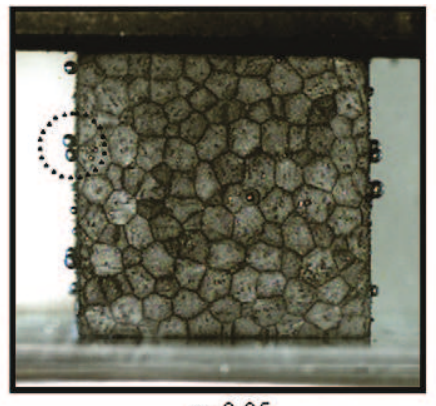

$e=0.05$

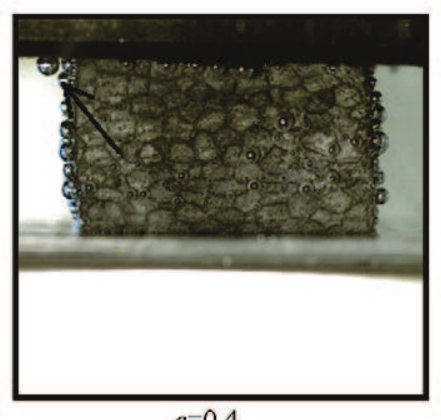

$e=0.4$

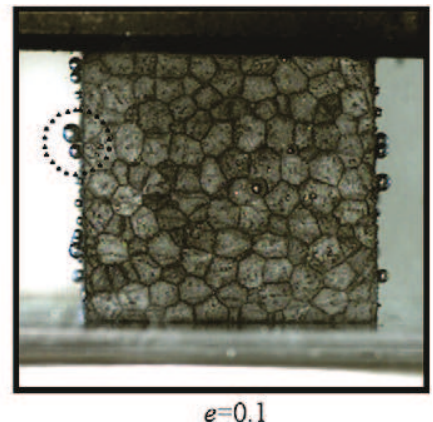

$e=0.1$

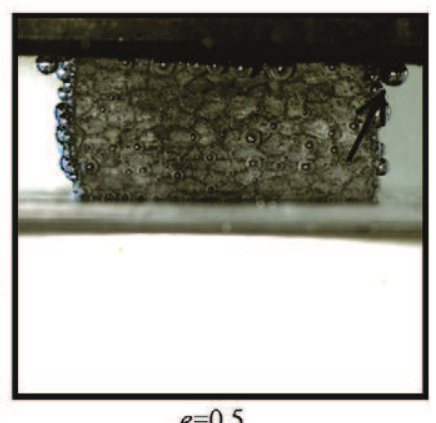

Fig. 25. Gas flow during quasi-static compression of EPP foam in water, $\dot{\varepsilon}=0.01 \mathrm{~s}^{-1}$ 


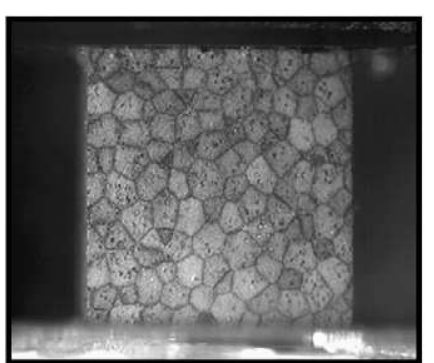

$e=0$

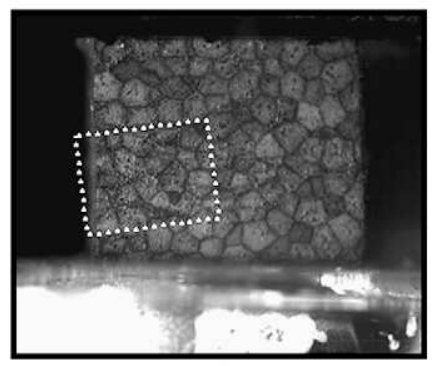

$e=0.2$

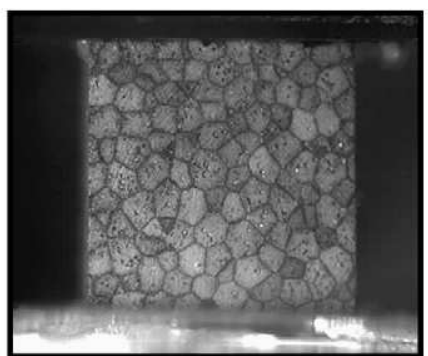

$e=0.025$

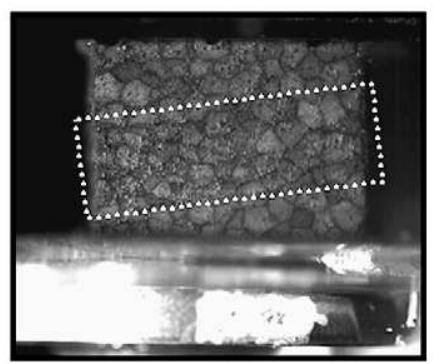

$e=0.3$

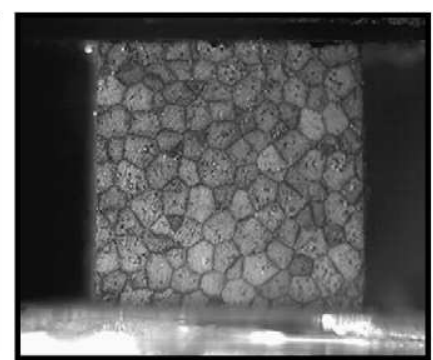

$e=0.05$

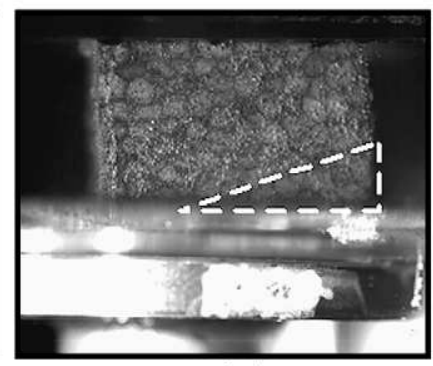

$e=0.4$

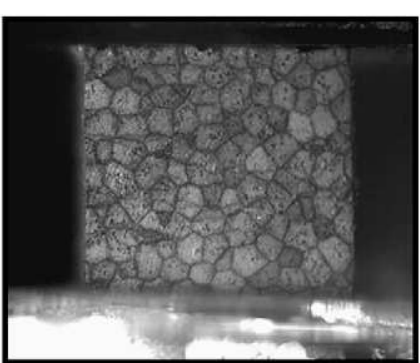

$e=0.1$

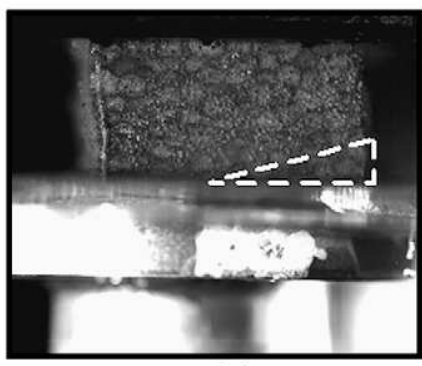

$e=0.5$

Fig. 26. Gas flow during intermediate strain rate compression of EPP foam in water, $\dot{\varepsilon}=200 \mathrm{~s}^{-1}$

so large that the gas must escape. From these observations it could be noticed that gas escapes in a non-continuous way in contrast to quasi-static tests but with a delay such as during the flywheel tests. Nevertheless this gas flow is not uniform and seems to be highly linked to the foam strain localization. Moreover we have to keep in mind that the observed phenomena are dependant on the specimen size: the larger the foam volume, the less gas escapes by squeezing. This remark implies that the accurate understanding of the gas contribution should be made by means of a microfluidic model and hence on the basis of tests at different scales and different speeds. Obviously, this would lead to experimental difficulties, as regards the SHPB assumptions and the possible facilities: on the one hand the coupling between the buckling of the walls and the confinement by pressure on the other hand.

From these experimental compression tests performed in water it can be concluded that gas bubbles do not appear for the same strain level but depend also on the strain rate. This delayed appearance of gas bubbles during compression highlights the dependence of the foam mean strain rate by contributing to the increase of the plateau stress modulus.

\section{Conclusion}

Compression tests have been performed on expanded polypropylene foams, and these tests on such compliant materials have highlighted the density effect on the foam behaviour. The foam strength increases according to the density, the higher the density: the thicker the bead and cell walls. This is a consequence of the increase of the bulk material in the foam.

The use of suitable specific devices such as a flywheel and a viscoelastic Split Hopkinson Pressure Bar makes it possible to highlight the foam sensitivity on a large range of loading velocities and at high strain rates. The strain rate hardening phenomenon is found to be more pronounced for higher density foams. The higher density foam is very sensitive above intermediate strain rates $\left(200 \mathrm{~s}^{-1}\right)$ whereas this phenomenon is less significant in this range of strain rates for the lower density foams. This phenomenon is correlated to the micro-inertia effects which are more pronounced on thicker (i.e. heavier) cell walls during the dynamic buckling of the foam cells. This hardening phenomenon is strongly marked by the effects of the entrapped gas in the closed cells. Compression

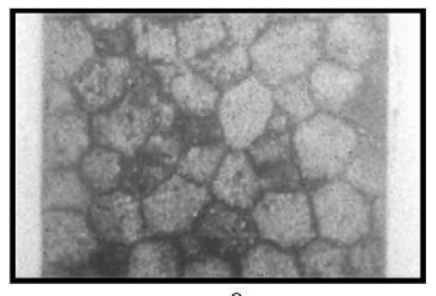

$e=0$

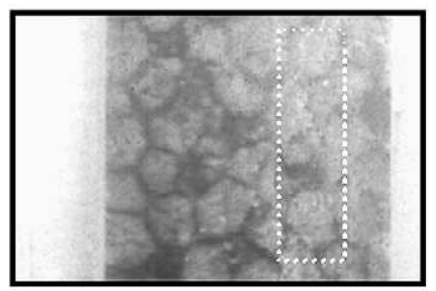

$e=0.2$

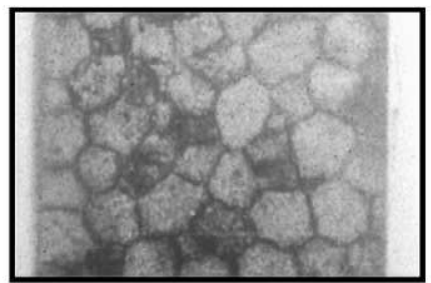

$e=0.025$

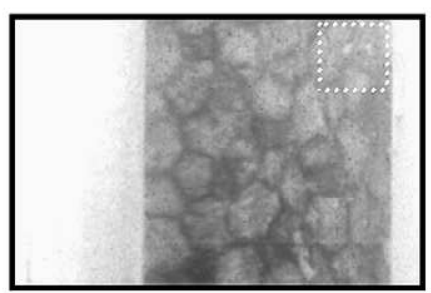

$e=0.3$

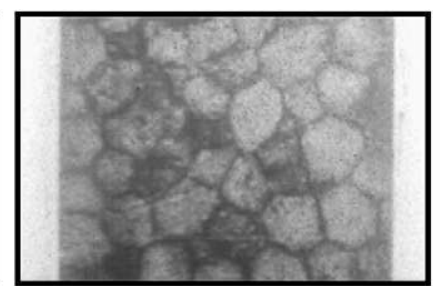

$e=0.05$

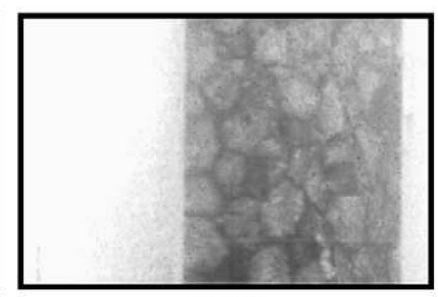

$e=0.4$

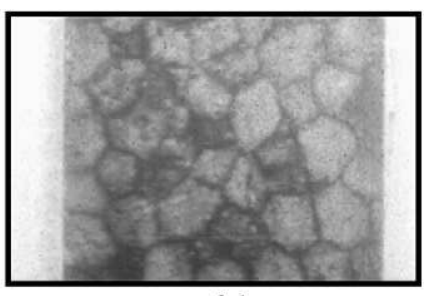

$e=0.1$

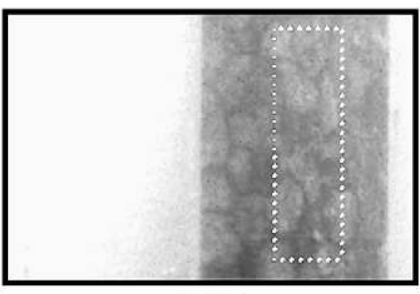

$e=0.5$

Fig. 27. Gas flow during SHPB test on an EPP foam in water, $\dot{\varepsilon}=1500 \mathrm{~s}^{-1}$. 


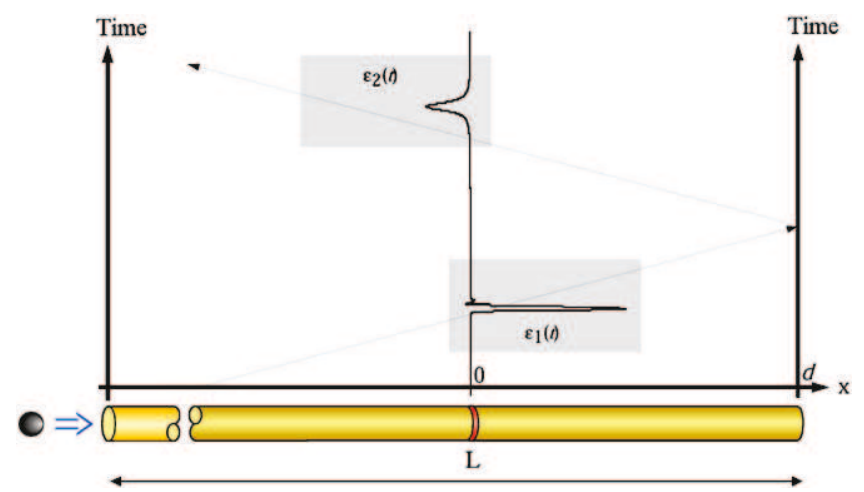

Fig. 28. Path of the pulse generated by impact, (Bacon 1998, [34]).

tests performed in a fluid chamber at quasi-static loadings have revealed that gas flow appears as soon as the foam is compressed. During dynamic tests, however, the gas doesn't have enough time to escape from the foam until the cell is totally crushed (dense), and thus is responsible for a large increase in the cell pressure as the volume rapidly decreases.

The foam microstructure has also been investigated by means of two microstructurally different expanded polypropylene foams of equal density. Quasi-static compressive strength of smaller cell sizes (shorter and thinner cell walls) are better than larger ones as they are less sensitive to bending and buckling, but they are less influenced by the strain rate. However, larger cells (longer and thicker cell walls) are more prone to bend or buckle during quasi-static loadings but are stronger under dynamic loadings as the micro-inertia effect makes them more difficult to bend or buckle.

\section{Appendix.}

\section{Theoretical one-dimensional wave propagation}

Let us consider a viscoelastic bar of cross section area $A$ and density $\rho$ axially impacted. The normal stress $\sigma(x, t)$ and the longitudinal strain $\varepsilon(x, t)$ are related to the axial displacement $u(x, t)$ at a cross section $x$ and at the time $t$ by:

$\frac{\partial \sigma(x, t)}{\partial x}=\rho \frac{\partial^{2}}{\partial t^{2}} u(x, t)$ and $\varepsilon(x, t)=\frac{\partial u(x, t)}{\partial x}$

From this Eq. (4), it is more convenient to write this relation in the Fourier domain with $\omega$ the angular frequency:

$\frac{\partial^{2}}{\partial x^{2}} \tilde{\sigma}(x, \omega)=-\rho \omega^{2} \tilde{\varepsilon}(x, \omega)$

where $\tilde{\sigma}(x, \omega)$ and $\tilde{\varepsilon}(x, \omega)$ denote the Fourier transform of the stress and strain, respectively. So the linear viscoelastic behaviour of the bar material is:

$\tilde{\sigma}(x, \omega)=E^{*}(\omega) \tilde{\varepsilon}(\mathcal{X}, \omega)$

where $E^{*}(\omega)$ is the complex Young's modulus of the material. So, a propagation coefficient $\gamma(\omega)$ can be defined as follows:

$\gamma^{2}(\omega)=-\frac{\rho \omega^{2}}{E^{*}(\omega)}$

This coefficient propagation $\gamma(\omega)$ is thus connected to the attenuation coefficient (or damping coefficient) $\alpha(\omega)$ and to the phase velocity $c(\omega)$ by: $\gamma(\omega)=\alpha(\omega)+i \frac{\omega}{c(\omega)}$

The expression of the one-dimensional equation of axial motion of a viscoelastic bar with Eqs. (4)-(6) becomes:

$$
\left.\frac{\partial^{2}}{\partial x^{2}}-\gamma^{2}(\omega)\right) \tilde{\varepsilon}(x, \omega)=0
$$

The general solution of this Eq. (9) is:

$\tilde{\varepsilon}(x, \omega)=\tilde{P}(\omega) e^{-\gamma x}+\tilde{N}(\omega) e^{+\gamma x}$

where $\tilde{P}(\omega)$ and $\tilde{N}(\omega)$ are the Fourier transforms of the strain at $x=0$ due to the stress incident and reflected waves propagating in the bar.

Then, from this Eq. (10) solution, the axial particle velocity $\tilde{v}(x, \omega)$ and the normal force $\tilde{F}(x, \omega)$ at the cross section $x$ are:

$$
\left[\begin{array}{c}
\tilde{F}(x, \omega) \\
\tilde{v}(x, \omega)
\end{array}\right]=\left[\begin{array}{cc}
-\frac{A \rho \omega^{2}}{\gamma^{2}} \times e^{-\gamma x} & -\frac{A \rho \omega^{2}}{\gamma^{2}} \times e^{+\gamma x} \\
-\frac{i \omega}{\gamma} \times e^{-\gamma x} & \frac{i \omega}{\gamma} \times e^{+\gamma x}
\end{array}\right]\left[\begin{array}{c}
\tilde{P}(\omega) \\
\tilde{N}(\omega)
\end{array}\right]
$$

\section{Determination of the propagation coefficient: principle}

Now, let us consider a finite bar with length $L$ impacted on one of its free faces (Fig. 28). It is possible to measure the longitudinal strain $\varepsilon_{1}(t)$ separately due to the incident stress wave and $\varepsilon_{2}(t)$ due to the stress wave reflected at the free non-impacted end of the bar, at a cross section $x$.

Since the non-impacted end of the bar is free, the normal force is zero, then Eq. (11) leads to:

$\tilde{P} e^{-\gamma d}+\tilde{N} e^{\gamma d}=0$

with $d$ the length between the signal measurement and the free non-impacted face. The solution of this transfer function gives the experimental propagation coefficient:

$e^{-2 \gamma d}=-\frac{\tilde{\varepsilon}_{2}(\omega)}{\tilde{\varepsilon}_{1}(\omega)}$

with $r(\omega)$ the modulus and $\theta(\omega)$ the phase of this transfer function; experimental attenuation coefficient and wave number $(k(\omega)=\omega /$ $c(\omega))$ are:

$\alpha(\omega)=-\frac{\ln r(\omega)}{2 d}$
$k(\omega)=\frac{\theta(\omega)}{2 d}$

\section{References}

[1] Lataillade JL. Dynamic tests. In: Francois D, editor. Structural components, mechanicals tests and behaviour laws, chapter 9. A. HERMES SCIENCE and LAVOISIER Company Publishers, ISBN 1905209185; 2006.

[2] Viot P, Beani F, Lataillade J-L. Polymeric foam behavior under dynamic compressive loading. Journal of Materials Science 2005;40:5829-37.

[3] Kolsky H. An investigation of the mechanical properties of materials at very high rates of loading. Proceedings of the Physical Society of London 1949;B62: 676-700.

[4] Davies EDH, Hunter SC. The dynamic compression testing of solids by the method of the Split Hopkinson Pressure Bar. Journal of the Mechanics and Physics of Solids 1963;11(3):155-79.

[5] Zhao H. Gary G. On the use of SHPB technique to determine the dynamic behavior of the materials in the range of small strains. International Journal of Solids and Structures 1996;33(32):3363-75. 
[6] Magd EEl, Abouridouane M. Characterization, modelling and simulation of deformation and fracture behaviour of the light-weight wrought alloys under high strain rate loading. International Journal of Impact Engineering 2006;32: 741-58.

[7] Bacon J, Färm C, Lataillade JL. Dynamic fracture toughness determined from load-point displacement. Experimental Mechanics 1994;34(3):217-23.

[8] Grote SW, Park DL, Zhou M. Dynamic behavior of concrete at high strain rates and pressures: I. experimental characterization. International Journal of Impact Engineering 2001;25:869-86.

[9] Frew MJ, Forrestal DJ, Chen W. A Split Hopkinson Pressure Bar technique to determine compressive stress-strain data for rock materials. Experimental Mechanics 2001;41(1):40-6.

[10] Thiruppukuzhi SV, Sun CT. Testing and modeling high strain rate behavior of polymeric composites. Composites Part B 1998;29B:535-46.

[11] Dannemann KA, Lankford J. High strain rate compression of closed-cell aluminium foams. Materials Science Engineering A 2000;293:157-64.

[12] Zhao I, Elnasri H, Abdennadher S. An experimental study on the behaviour under impact loading of metallic cellular materials. International Journal of Mechanical Sciences 2005;47(4-5):757-74

[13] Chen F, Lu W, Winfree N. High-strain rate compressive behavior of a rigid polyurethane foam with various densities. Experimental Mechanics 2002; 42(1):65-73.

[14] Dou W, Winfree S, Song NA, Chen B, Kang JH. Strain-rate effects on elasic and early cell-collapse responses of a polystyrene foam. International Journal of Impact Engineering 2005;31:509-21.

[15] Zhao H. Testing of polymeric foams at high and medium strain rates. Polymer Testing 1997; 16:507-16.

[16] Frew F, Chen DJ, Lu W, Forrestal MJ. Dynamic compression testing of soft materials. Journal of Applied Mechanics 2002;69(3):214-23.

[17] Zhao G, Gary H, Klepaczko JR. On the use of a viscoelastic Split Hopkinson Pressure Bar. International Journal of Impact Engineering 1997;19(4):319-30.

[18] Azari K, Wang Z, Labibes L, Pluvinage G. Generalization of Split Hopkinson Bar technique to use viscoelastic bars. International Journal of Impact Engineering 1994;15(5):669-86.

[19] Chen B, Zhang W, Forrestal MJ. A Split Hopkinson Bar technique for lowimpedance materials. Experimental Mechanics 1999;39(2):81-5.

[20] Gibson LJ, Ashby MF. Cellular solids: structure and properties. 2nd ed. Cambridge University Press; 2001.

[21] Mills NJ, Zhu HX. The high strain compression of closed-cell foams. Journal of the Mechanics and Physics of Solids 1999;47:669-95.

[22] Avalle G, Belingardi M, Montanini R. Characterization of polymeric structural foams under compressive impact loading by means of energy-absorption diagram. International Journal of Impact Engineering 2001;25:455-72.

[23] Mills NJ, Lyn G. Modelling of air flow in impacted polyurethane foam. Cellular Polymers 2002;21(5):343-67.

[24] Mills NJ, Gilchrist A. Shear and compressive impact of polypropylene bead foam. Cellular Polymers 1999;18(3):157-74

[25] Viot P, Plougonven E, Bernard D. Microtomography on polypropylene foam under dynamic loading. 3d analysis of bead morphology evolution. Composites Part A, under review.
[26] Viot P, Beani F. Comportement de mousses polymères en compression dynamique. Revue des Composites et des Matériaux Avancés, vol. 13(no. 3); 2003. p. 283-92, ISBN: 2-7462-1117-3.

[27] Charles C, Lambert J-L, Froustey M, Lataillade J-L. High strain rate testing of aluminium alloy and high speed photography. Journal de Physique IV 2003 110:543-9.

[28] Sawas NS, Brar O, Brockman RA. Dynamic characterization of compliant materials using an all-polymeric Split Hopkinson Bar. Experimental Mechanics 1998;38(3):204-10.

[29] Bacon C, Lataillade JL. Development of the Kolsky-Hopkinson techniques and application for non-conventional testing. Institute of Fundamental Technological Research Polish Academy of Sciences - Centre of Excellence for Advanced Materials and Structures; 2001, ISBN: 83-910387-7-7.

[30] Casem WL, Fourney DT, Chang P. A polymeric Split Hopkinson Pressure Bar instrumented with velocity gages. Experimental Mechanics 2003;43(4):420-7.

[31] Gray GT, Blumemthal WR. "Split-Hopkinson Pressure Bar Testing of Soft Materials," Mechanical Testing and Evaluation, Metals Handbook. American Society for Metals, Materials Park, Ohio 2000;8:488-96.

[32] Zhao H, Gary G. A three dimensional analytical solution of the longitudinal wave propagation in an infinite linear viscoelastic cylindrical bar: application to experimental techniques. Journal of the Mechanics and Physics of Solids 1995;43(8):1335-48.

[33] Mahata S, Mousavi K, Söderström T. On the estimation of complex modulus and Poisson's ratio using longitudinal wave experiments. Mechanical Systems and Signal Processing 2006;20:2080-94.

[34] Bacon C. An experimental method for considering dispersion and attenuation in a viscoelastic Hopkinson bar. Experimental Mechanics 1998;38(4):242-9.

[35] Bacon C. Methodology for a Hopkinson test with a non-uniform viscoelastic bar. International Journal of Impact Engineering 2000;24:219-30.

[36] Pochhammer L. On the propagation velocities of small oscillations in an unimited isotropic circular cylinder. J die Reine Angew Math 1876;81:324-36.

[37] Chree C. The equations of an isotropic elastic solid in polar and cylindrica coordinates, their solutions and applications. Transactions of the Cambridge Philosophical Society 1889;14:250.

[38] Hopkinson B. A method of measuring the pressure produced in the detonation of high explosives or by the impact of bullets. Philosophical Transactions of the Royal Society of London 1914;A213:437-56.

[39] Zhao H. Material behaviour characterisation using SHPB techniques, tests and simulations. Computers and Structures 2003;81:1301-10.

[40] Gama SL, Lopatnikov BA, Gillespie Jr JW. Hopkinson bar experimental technique: a critical review. Applied Mechanics Reviews 2004;57(4):223-50.

[41] Yang LM, Shim VPW. An analysis of stress uniformity in Split Hopkinson Bar test specimens. International Journal of Impact Engineering 2005;31:129-50.

[42] Zhao H. A study of specimen thickness effects in the impact tests on polymers by numeric simulations. Polymer 1998;39(5):1103-6.

[43] Lopatnikov BA, Gama SL, Gillespie JW. Modeling the progressive collapse behaviour of metal foams. International Journal of Impact Engineering 2007;34 587-95.

[44] ZeBuloN. User manual. Transvalor/ENSMP-Centre des matériaux, BP87-91003 Evry Cedex, http://www.mat.ensmp.fr 